\title{
دور القضاء الوطنى فى تسيير إجراءات التحكيم التجارى ( دراسة هقارنة )
}

\author{
shel \\ د./ سعدل بن سعيد الذيابى \\ أستاذ مشارك بقسم القانون ككليت الأعمال ـ جامعت جدة \\ عميد كليتت الشربعتش والأنظمت بجامعتشتبولك
}




\section{هقدمهــة}

\section{* تعريف بالموضوع وأهـيتيته:}

يعرف التحكيم بأنـه الاتفـق على طرح نزاع على شخص أو أشخاص معينين

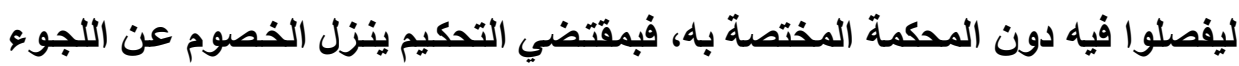
للقضاء('). وقد يكون التحكيم وارداً في عقد أو اتفاق مسبق ويسمي بشرط التحكيم(')، وقد يكون بمناسبة نزاع قائم ويسي مشارطة التحكيم (")،وويقوم القضاء الوطني بمساعدة هيئات التحكيم في مرحلة انعقـاد الخصومة التحكيمية، والتي تعتبر السبيل الذى يُتخذ وصولاً للهدف من اختيار طريق التحكيم لتسوية المنازعات، فهي بمثابـة القواعد التي يقف عليها البنيان، ويكون دور القضاء دائمـاً لمواجهة مـا تعجز إرادة

$$
\begin{aligned}
& \text { (1) د.حسنى المصري ـ التحكيم التجـاري الدولي دراسـة مقارنـة ـ دار الكتب القانونيـة ـ مصر - }
\end{aligned}
$$

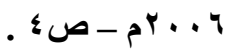

ـ ــ أبو زيد رضوان ـ الأسس العامة في التحكيم التجاري الدولي ـ دار الفكر العربي ـ مصر-

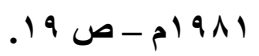

- ويعرف البعض التحكيم بأنه إرساء عدالة خاصة بفضلها تحال النزاعات من قضاء القانون العام ليفصل فيها من قبل الأفراد. - ائه

- Jean Robert L'arbitrage : droit interne et droit international - 6éme Editions - Dalloz- 1993 -page p.3.

(ץ) د. فوزي محمد سـامي - التحكيم التجاري الدولي"دراسـة مقارنـة" في أحكام التحكيم التجاري

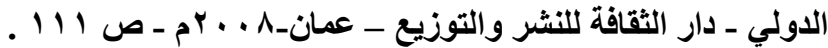

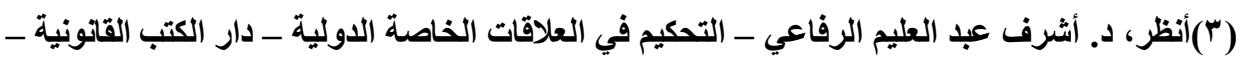

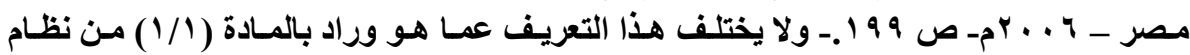

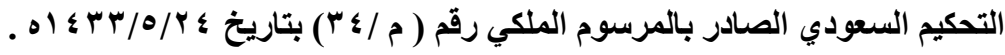


الأطراف عن تفاديه، ولا يفلح اتفـاق التحكيم أو النظام في تخطيه، ففي هذه المراحل يتدخل القضاء لمساعدة هيئات التحكيم في إتمام عملها . ففي المراحل الأولى يتدخل القضاء لـرد الـدعوى لعدم القبول، وكذلك تعيين المحكمين وردهـم، وعزلهم، ثم إذا مـا انعقدت الخصومة صـحيحة، يتـخل القضاء الوطني لمساعدة الأطراف وهيئة التحكيم في اتخـاذ مـا يلزم من إجراءات تحفظية أو

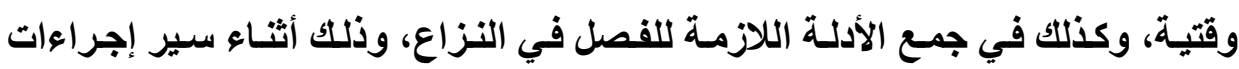
التحكيم. وقد عكف المـظظم السعودي على تـــاول موضـوع التحكيم مـن خـلال الأنظمـة التي يصدرها نظراً لاهتمامه بهذا النظام بـالغ التأثير في الحياة العملية، فقد صدر في مدي المملكـة العربيـة السعودية نظـام التحكيم بالمرسـوم الملكـي رقـم (م / ع ب) وتـاريخ

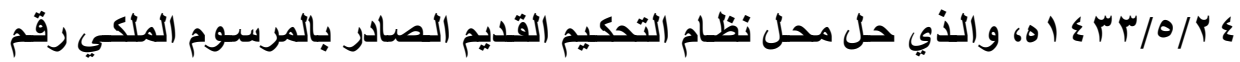

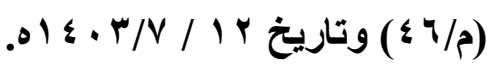

* إثـــالية الدراســة: يتــخل القضاء الـوطني إلـى جانب هيئـات التحكيم لإنجـاز العدالـة بصفته مسساعداً لهـا، وهو مـا دفعنـا للتساؤل عن الـدور الــى يؤديـه القاضى الوطنى فى مرحلة انعقاد الخصومة التحكيمية؟ وعن دوره فى مرحلة سير الاجراع|ت؟.

لذا تعين علينا دراسـة هذا الدور وتحديد مداه وأثره على عملية التحكيم، من خلال بحث دور القضاء الوطنى فى تسيير إجراعات التحكيم التجارى . * هناهج البحث : يعتمد البحث على المنهج التحليلى والمنهج المقارن فى تناول موضوعات البحث . 
* خطة البحث : ينقسم البحث إلى مقدمة، وفصلين، وخاتمة، وذلك على النحو

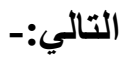

الفصل الأول : دور القضاء الوطني في مرحلة انعقاد الخصومة التحكيمية .

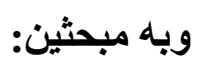

$$
\text { - المبحث الأول : رد الدعوى لعدم القبول . }
$$

- المبحث الثانى : دور القضاء الوطنى فى تعيين المحكمين وردهم .

الفصل الثاني : دور القضاء الوطني في مرحلة سير إجراءات التحكيم .

$$
\text { وبه ثلاثة مباحث : }
$$

- المبحث الأول : دور القضاء الوطنى فى اتخاذ اتدابير الوقتية والتحفظية. - البحث الثانى : مساعدة القضاء الوطني هيئة التحكيم في جمع الأدلة . - المبحث الثالث: دور القضاء الوطني فى الفصل في المسائل الأولية . - خاتمة البحث: وتثمل على أهم النتائج والتوصيات . 


\section{الفصل الأول}

\section{دور القضاء الوطني في هرحلة انعقاد الفصوهة التمكيمية}

يقوم التحكيم بدور فعال فى فض المنازعات التجاريـة (') في العصر الحديث، إلا أنه لا يمكنه التخلي عن الحاجة للقضاء الوطني(† ) كمساعد له، والذى قد يتلخل في مرحلة إنعقاد الخصومة التحكيمية،على الرغم أن الهدف من وجود التحكيم هو التيسير والسرعة في إنهاء النزاعـات()، و بغرض البعد عن القضاء الوطني الذي قد يطول أمامه أمد أي نزاع، وخاصة النزاعات المتعلقة بالتجارة. وتكون الجهات القضائية صاحبة الاختصاص في عدة مسائل قد تؤثر على صحة انعقاد الخصومة التحكيمية، وتظهر في مراحلها الأولى،ولا يمكن حلها بالإرادة المنفردة

(1) Ph. Fouchard, -L'arbitrage et la mondialisation de l'économie», Mélanges en l'honneur de Gérard Farjat, Paris, 1999, p. 381 ـ أنتثر التحكيم في العصر الحديث إلى درجة إنه قلما نجد عقداً من عقود التجارة الدولية يخلو من

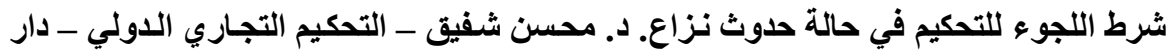

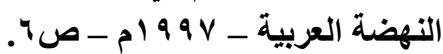

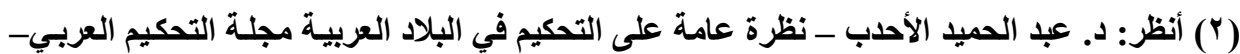

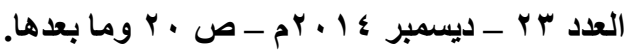

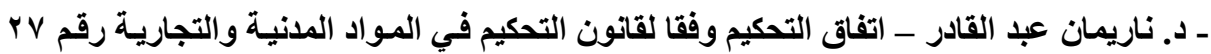

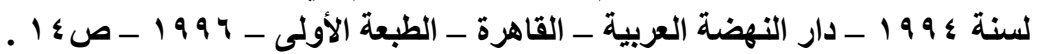
(") حيث يفرض التحكيم نفسه كبديل عن اللجوء للقضاء بقوة لما يتميز به من سرية وسرعة وغيرها

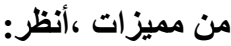

-Fouchard, Gaillard et Goldman, Traite de l'arbitrage commercial international, ed. Litec, Paris, 1996. No. 12,p.14. 
للأطراف، أو بنـاء على اتفـق التحكيم، لهذا نجد أغلب القوانين ومنهـا نظـام التحكيم

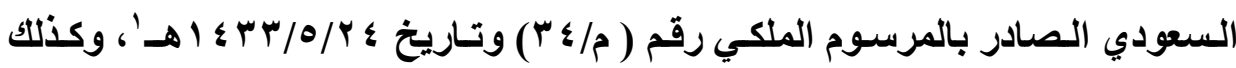

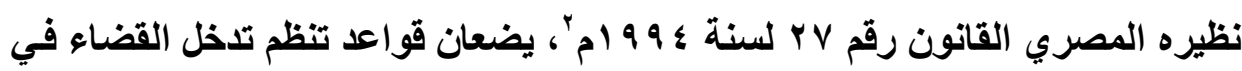
مرحلة انعقاد الخصومة التحكيمية لمساعدة هيئة التحكيم في إنجاز مهمتها، فالمحاكم تقضى بعدم قبول الدعوى لوجود شرط التحكيم، وقد يكون دور القضاء هو تعيبين المحكمين،أوردهم،أو عزلـه مفي حالـة قصور إدارة الأطراف في القيـام بـلك، وحلقة الوصل بين هذه التدخلات هي أنها جميع آقد تكون قبل البدء في سير إجراءات التحكيم، وهو ما سنتناوله على النحو التالي :

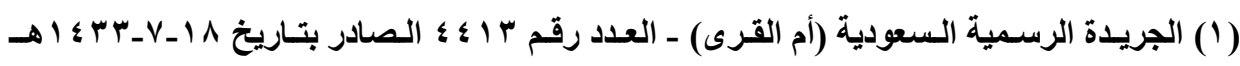

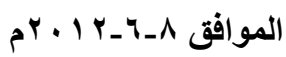

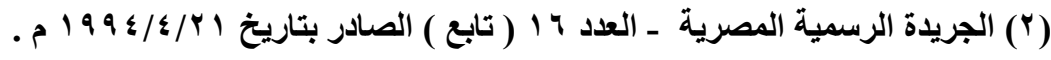




\section{المبحث الأول}

\section{رد الدعوي لهدم القبول (1)}

وجود اتفاق تحكيم مسبق بخصوص نزاع معين يلقي التزامـاً على طرفيها بعدم

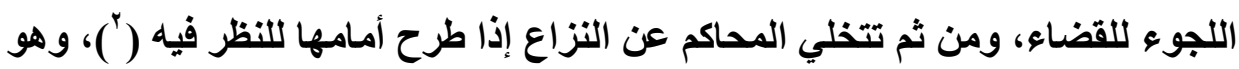
أمر تتفق فيه أغلب التشريعات(")، فنظام التحكيم السعودي في المادة (11) منه،هوكنلك

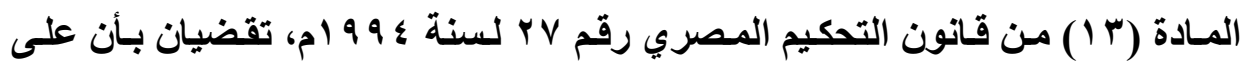
المحكمة التي يرفع إليها نزاع يوجد بثأنه اتفاق تحكيم أن تحكم بعدم قبول الدعوي إذا دفع المدعي عليه بذلك قبل إبداء أي طلب أو دفع في الدعوي على أن لا يحول رفع الدعوي المشار إليها دون البدء في إجراعات التحكيم أو الإستمرار فيها، أو إصدار حكم

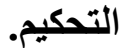

ويهرف المنظم السعودي من وراء هذا النص ألا يُتخذ رفع الدعوي أمام الجهات القضائية الوطنية وسيلة لتعطيل الهيئات التحكيمية عن أداء عملها، والمماطلة بقصد الإضر ار بالطرف الأخر.

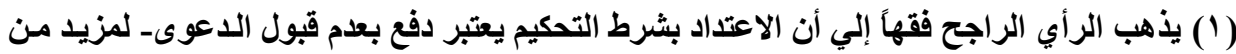

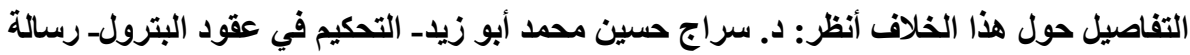

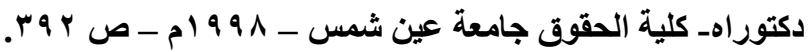

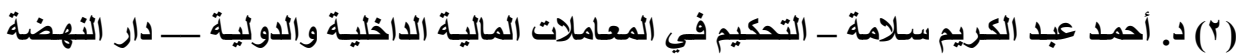

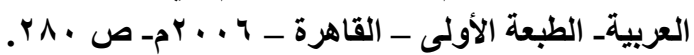

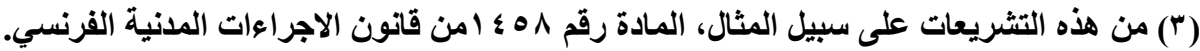
-Inséré par Décret n 81-500 du 12 mai 1981 - Journal Officiel du 14 mai 1981- rectificatif JORF 21 mai 1981. 
كما أن إحالة النزاع المعروض على القضاء الوطني والذي يوجد بشأنه اتفـاق تحكيمه و مجرد تنفيذ لإرادة المتعاقدين، فلا يجد الطرف الذي اتفق على إخضاع النزاع

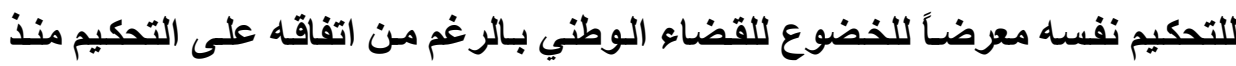
البدايـة، وهو الأمـر الذي ينـافي الاسـتقرار في المعـاملات ويقلـل مـن أهميـة التحكيم عموماً.

وعلى الرغم من تبنى هذا المبدأ من قبل الاتفاقيات الدولية الخاصـة بـالتحكيم التجاري الدولي (') وأغلب التشريعات الوطنية،نجد أن بعض القوانين تعتبر أي اتفـق ينزع الاختصاص القضائي للمحاكم الوطنية يعتبر باطلاً، كالقانون الانجليزي باعتبار أن ذللك مخالفاً للمبادئ القانونية السائدة)(ب) والتى تعتبر أنـه لايمكن الاتفـق على إنتزاع اختصاص المحسكم(")، إلا أن هذا القول لـم يعـد معـولاً بـه، فالمـادة (9) مسن قـانون

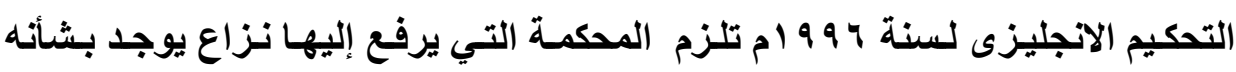

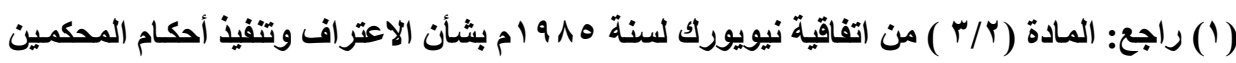

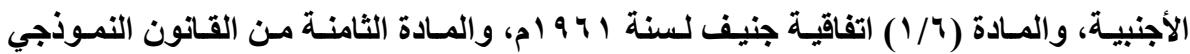

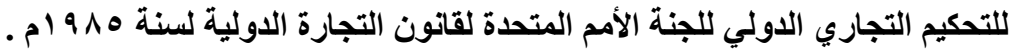

(2) Anne Bihancov -What is an example of a good dispute resolution clause and why?-Australian Centre for Justice Innovation Civil Justice Research Online- 2014- p 3,4.

(rot V. Avery (1856) 5 House of Lords. Case 118 : راجع فى ذلك (r) -Andrew Tweeddale and Keren Tweeddale- Scott $v$ Avery Clauses: O'er Judges' Fingers, Who Straight Dream on Fees- Swiss Cottage- 2011- pp 423 : 427.

-Michael H.LeRoy -Misguided Fairness - Regulating Arbitration by Statute: Empirical Evidence of Declining Award Finality- Notre Dame Law Review- Volume 83 - Issue 2- Article3 - p 568. 
إتفاق تحكيم أن تقضى برد الدعوى إذا دفع المدعى عليه بثرط التحكيم قبل الاخول فى

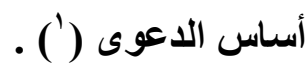

وقد اعتبر القضاء السعودي وجود اتفاق التحكيم - في ظل نظام التحكيم الصادر

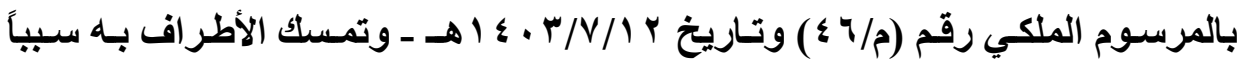

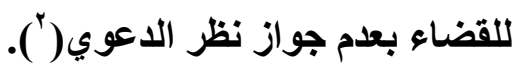
وتعتبر محكمسة الـنقض المـصرية(")سـكوت المسشرع المسصري في قـانون المرافعات المدنية والتجارية عن أثر الاتفاق السالب للاختصاص لا يمكن اعتباره رفضاً له، وذلك في حالة اختيار أطراف النزاع التحكيم كوسيلة لفض النزاع، وهذا مـا تبنـاه قانون التحكيم المصري صراحة في أحكامه. ورد المحاكم الوطنية للاعوي لعدم القبول في هذه الحالة يعتبر دوراً مساعداً في

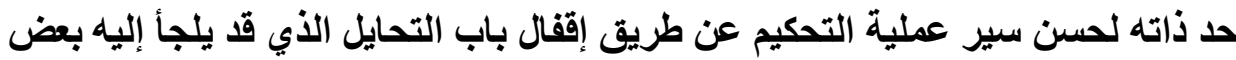

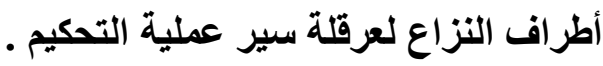

(1) Arbitration Act 1996 (of England), chapter 23 (17th June 1996 )

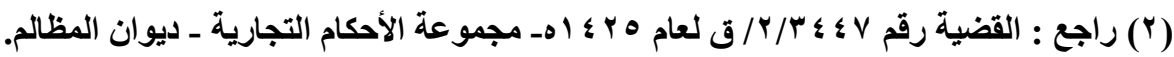

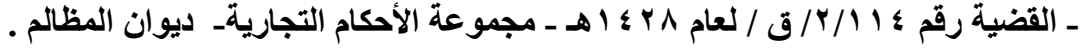

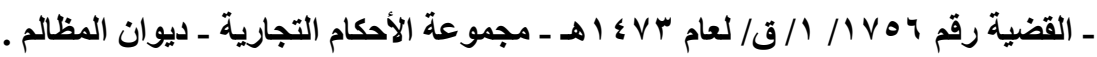

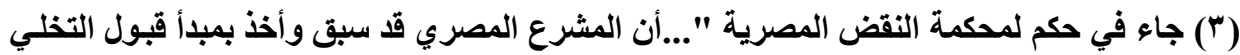

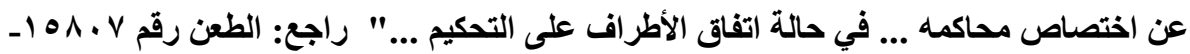

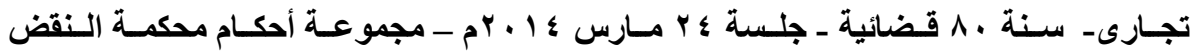

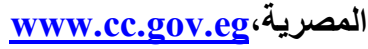


والدفع بعدم القبول لوجود اتفـق تحكيم لا يعتبر من النظام العـام، ولا تثيره المحكمة من تلقاء نفسها وإنما ينبغي أن يدفع به أحد الخصوم (') قبل تقديم أي طلب

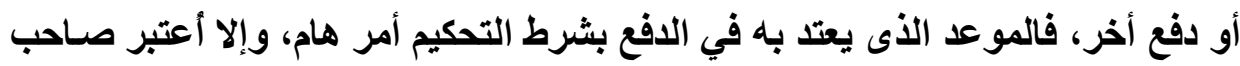

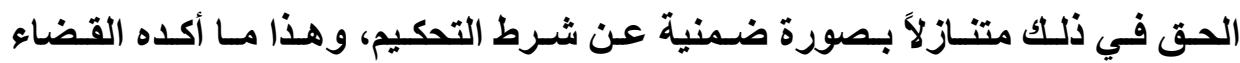
السعودي (r) حيث تمسك المدعى عليه بشرط التحكيم،وذلك في أول إجابة، وأعتبرته المحكمة سبباً للحكم بعدم جواز نظر الدعوى.

أما اذا اتفق الأطراف على التنازل صراحة عن شرط التحكيم فتصبح بنـاء على ذلك المحاكم الوطنية هي صاحبة الاختصاص بنظر النزاع. وقد يقوم أحد الأطراف برفع الدعوي أمام الجهات القضائية الوطنية المختصة، ويحضر المدعي عليه إلى المحكمة، ولا يبدي إعتراضـاً فهل يعتبر بذلك قد تنازل عن شرط التحكيم ضمنياً؟ يفهم بالمخالفة لنص المـادة (1 / / 1)مـن نظام التحكيم السعودي

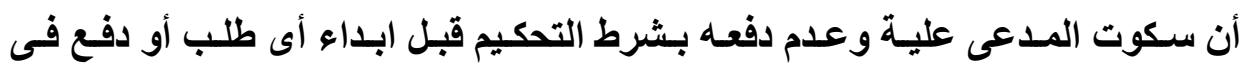

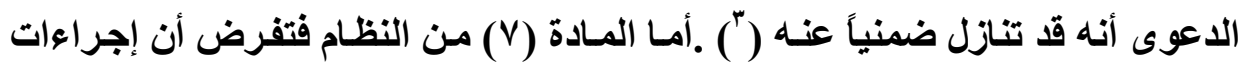

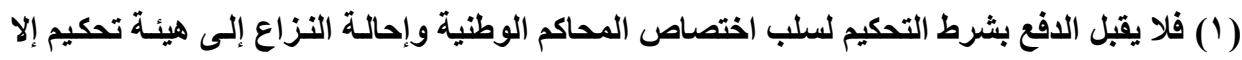

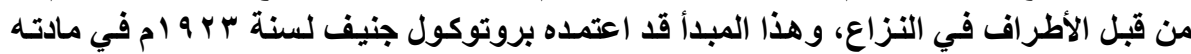

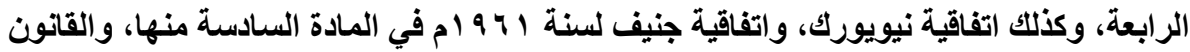

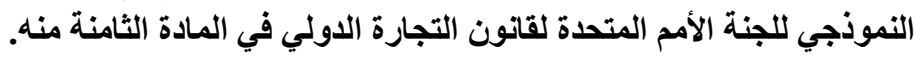

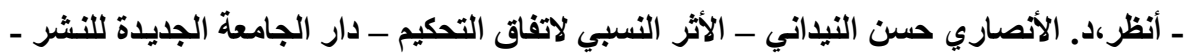

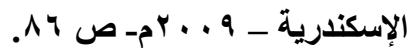

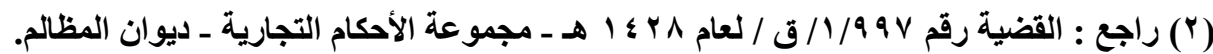

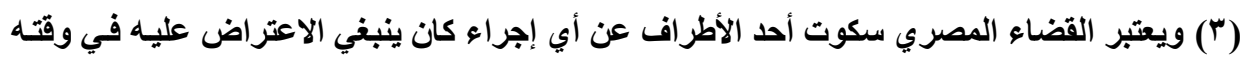

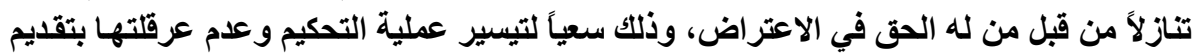
دفوع مختلفة مع سير مراحل عملية التحكيم. $=$ 
التحكيم قد بدأت وأن أحد الأطراف كان له الحق في الاعتراض على إجراء معين، ثم لـ يفعل واستمر في إجراعات التحكيم، فيعتبر بذلك قد تنازل عن حقه في الاعتراض، أمسا في هذا الفرض فالطرف الأخر في اتفاق التحكيم لا يدفع بشرط التحكيم أمسام المحكمة التي يعرض عليها النزاع، ومن ثم يعتبر قد تنـازل ضمنياً عنههووقد يرفع النزاع في بعض الحالات إلى المحاكم الوطنية المختصة، ولا يمنعها من نظرهـا دفع المدعي عليه بوجود شرط التحكيم، وذلك في الحالة التي يكون فيها اتفاق التحكيم بـاطلًا أو لاغياً أو غير قابل للتفيذ (')، وهو ما يعنى أن على القاضي قبل كل شيء أن يفصل في صحة اتفاق التحكيم.

وهذا الحكم لم يتناولـه نظام التحكيم السعودي، وإن كنـا نـري بضرورة النص على ذلكك باعتباره من المسائل بالغة الأهمية والتي قد يتعرض لها القاضي الوطني الذي يرفع إليه نزاع يوجد بخصوصه اتفـاق تحكيم باطل أو غير قابل للتنفيذ، كما لو كان اتفاق التحكيم مخالفاً للنظام العام في المملكة.

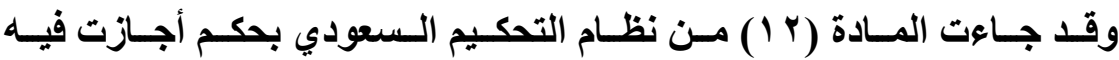
الاتفاق على التحكيم بعد رفع الدعوي أمام المحكمة المختصة، وذلك مع مراعاة ما جاء فـي المــادة (9/9)، وفـي هـذه الحالــة يجـب علـى المحكمـة أن تحيـل النـزاع إلـي التحكيم، ونري بأن المنظم السعودي قد أحسن صنعاً بهذا النص حين أجـاز للأطراف

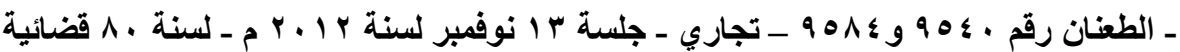

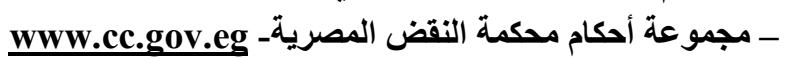
(1 ) راجع حكم محكمة النقض الفرنسية : -Arrêt $n^{\circ} 1764$ du 22 novembre 2005Cour de cassation - Première chambre civile . www.courdecassation.fr. 
الاتفــق على التحكيم - وذلـك في المسـائل التي يجـوز فيهـا التحكيم - بـالرغم مسن نظر الدعوي أمام المحكمة المختصةـ فقد يري أطراف النزاع أن التحكيم سيكون أكثر

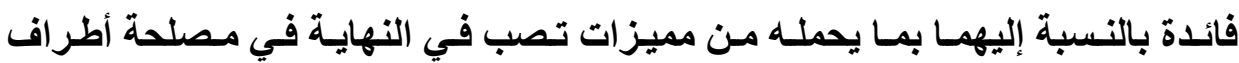
اللدعوي (')، وفى هذه الحالـة تصبح المحكمة هي صساحبة الاختصاص بالفصل في النزاع.

(1) يتماشى نظام التحكيم السعودي في ذلك مع أغلب التشريعات العربية، كالتشريع الأردني في المادة

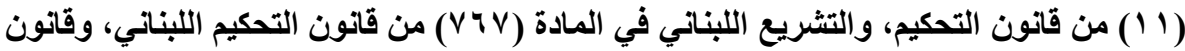

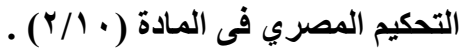




\section{المبحث الثاني \\ دور القضاء الوطني في تعيين المكمين وردهم وعزلهم}

الأصل أن اختيار المحكمين يكون من قبل الأطر اف المتفقة على حل النزاع عن

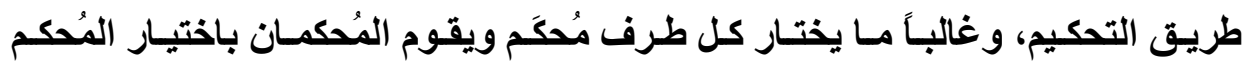

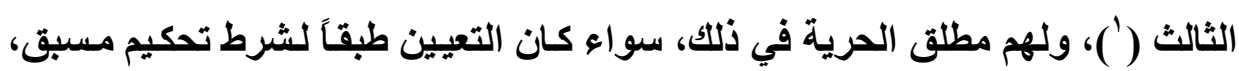
أو كان الاتفـاق على التحكيم بمناسبة نزاع قائم، ويتلدخل القضاء الوطني في تعيين المحكمين في حالة قصور إرادة الاطراف في تعين المحكمين، أو عدم الاتفاق على ذلك، ولا يمكن أن يتـلـل القضاء في تعيبين المحكمسين إلا إذا كانت هنـاك حاجـة إلى ذلـك،

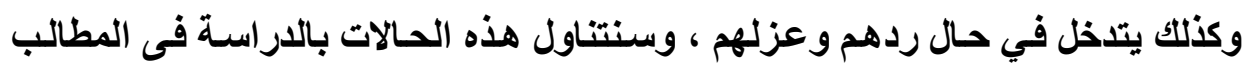

\section{المطلب الأول}

\section{دور القضاء الوطنبي في تعيسن الأمكيمين}

من المعروف أن التحكيم الحر أو الخاص والذى يقوم فيه أطر اف النزاع باختيار المحكمين بنـاء على قناعـاتهم الشخصية وثقتهم يجعل موضوع تشكيل هيئة التحكيم

(1) أنظر، د. أنور على أحمد الطثي - مبدأ الاختصاص بالاختصاص في مجال التحكيم - دار النهضة

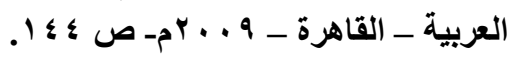

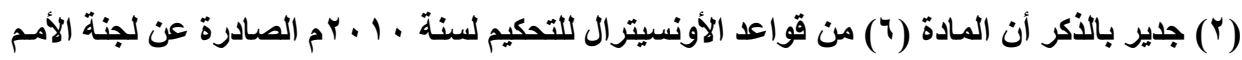

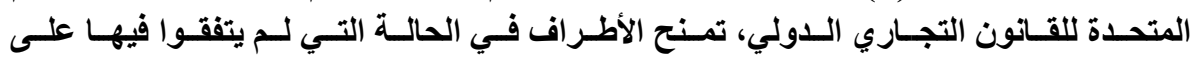

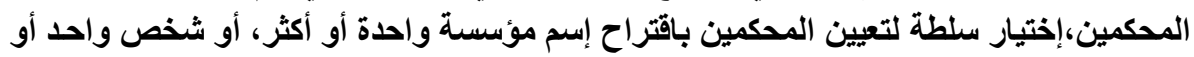
أكثر لتولى مهام سلطة التعيين. 
يبذو أمراً يسيراً، ولكن الحقيقة قد لا تكون بهذه البساطة، فقد يتفق الأطراف على حل

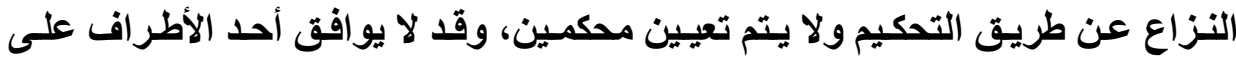

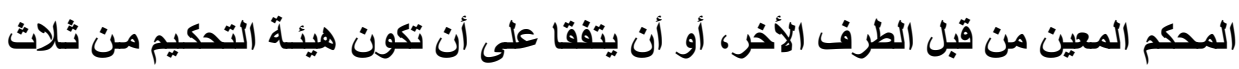

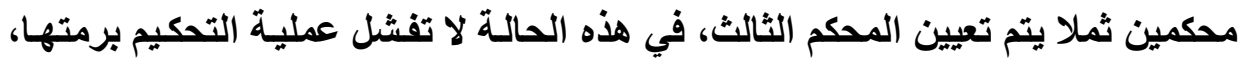

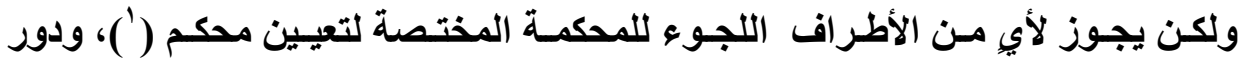

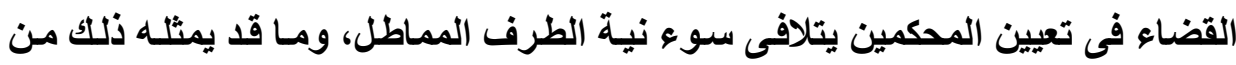

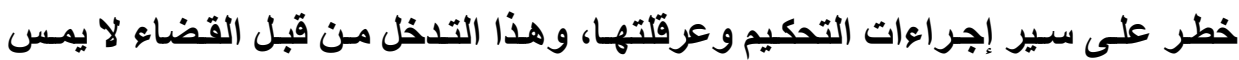
إستقلال عملية التحكيم، وإنما هو من قبيل المساعدة . ويتناول نظام التحكيم السعودي في المادة(10 / / / أ، ب) مسألة تلخل القضاء في تعيين المحكمين، وذلك على النحو التالي:أولاً: الحالة التي يكون فيها المحكم واحداً،وفي هذه الحالة إذا لم يتم الاتفـق من قبل الأطراف على اختياره تقوم المحكمة المختصة طبقاً للنظام باختيار المحكم، وذلكت

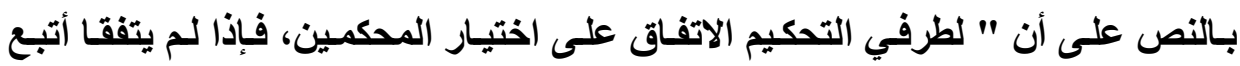

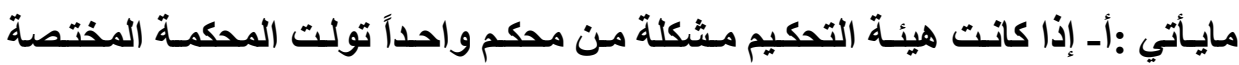

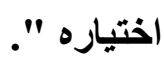

(1) جدير بالذكر أن تعيين المحكمين سواء كان من قبل الأطراف في اتفاق التحكيم، أو من قبل فئل

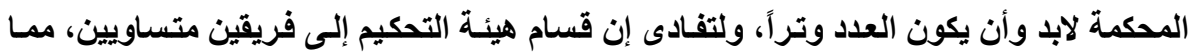

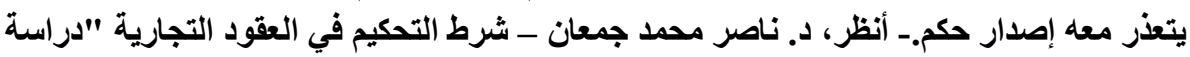

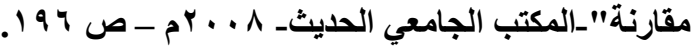


ثانيا: الحالة التي تكون فيها هيئة التحكيم مكونة من ثلاثة محكمين يتولى كل طرف اختيار محكم، ثم يقوم المحكم ان باختيار المحكم الثالث (')، وفي هذا الفرض قدان لاند لا يتمكن المحكمان من اختيار ثالثهمـا لأى سبب كان، أو لايقوم أحد الأطراف بتعيين

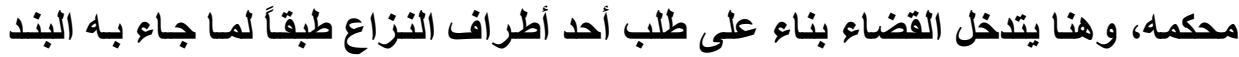
(ب) من الفقرة (1) حيث نص على أنسه" إذا كانت هيئة التحكيم مشكلة مـن ثلاثة محكمين اختار كل طرف محكماً عنه،ثم يتفق المحكم ان على اختيار المحكم الثالث، فباذا

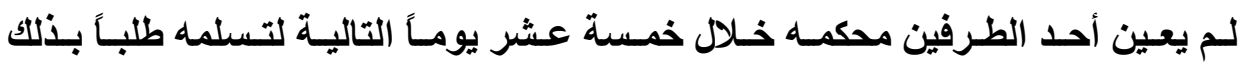
من الطرف الآخر، أو إذا لم يتفق المحكمان المعينـان على اختيار المحكم الثالث خلال

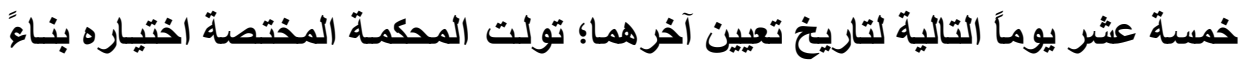
على طلب من يهمـه التعجيل، وذلك خلال خمسة عشر يومـاً من تاريخ تقديم الطلب، ويكون للمحكم الذي اختاره المحكمـان المعينـان،أو الذي اختارته المحكمة المختصة

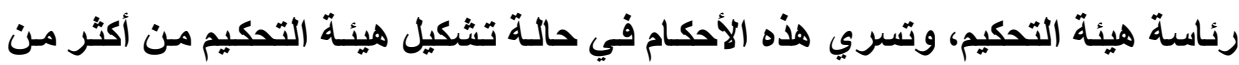

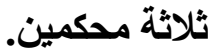

و الواضح من هذا النص أنه يسري في الحالات التي تكون فيها هيئة التحكيم

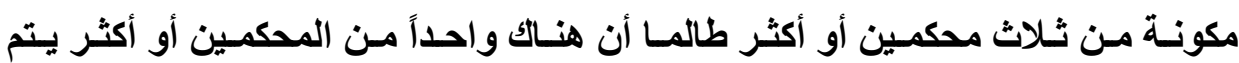

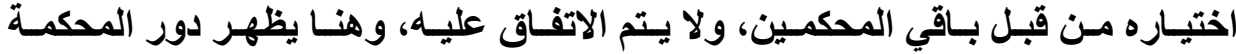

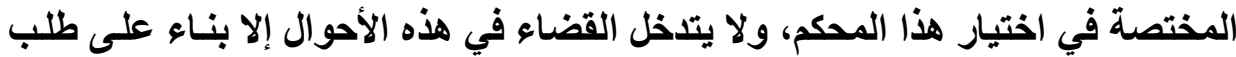
من يهمه التعجيل من الأطراف.

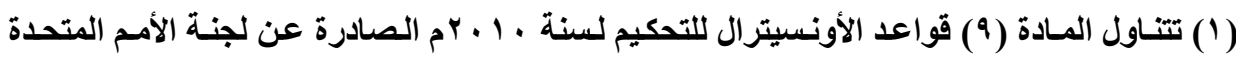

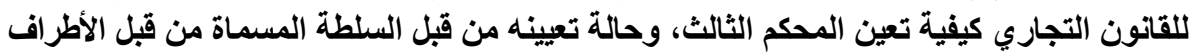


وبهـذه الطريقـة يسـد نظـام التحكيم السعودي بـاب التحايـل، ومــاقد يعترى عملية التحكيم من تعطيل في تثكيل هيئة التحكيم سواء كاتت مكونة من محكم واحد أو

وتلتزم المحكمة في هذه الحالة بالثروط التي نص عليها اتفاق التحكيم لاختيار المحكمين، وكذلك الثروط التي يتطلبها النظام، وتصدر قرارهـا بـالتعيين خلال ثثلاثين

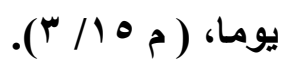

وعلى المحكمة أن تتبع الاجراءات التي نص عليها الاتفاق لتعيين المحكمين، ما لم يخلو الاتفاق من النص على هذه الاجراءات، وهنا عليها أن تتبع الإجراءات الواردة

$$
\text { في نظام التحكيم (م } 10 \text { / ع ). }
$$

ويكون للأطراف الحق في اللجوء للمحكمة في حالة عدم اختيار الخصم للمحم بعد مضى خمسة عشر يومـاً من تاريخ تسليمه الطلب للطرف الأخر، أو عدم اختيار المحكمين للمحم الثالث خلال مدة مماثلة.

وهنا يثور التساؤل في الحالة التي لا يؤدى فيها المحكم الذى تم تعينه من قبل المحكمة عمله لأي سبب كان، كأن يعتذر، أو يرفض إستكمال عمله، فهل يجوز للطرف المتضرر اللجوء للقضاء مرة أخرى لطلب تعيين محكم؟. نعتقل أنه ليس هنالك مـا يمنـع ذلك، فالخصم الأخر قد أبدى سوء نيتها، وعدم تعاونه، لذا من العدل أن يكون من حق المدعى أو من يهمـه التعجيل اللجوء للقضاء مباشرة دون حاجة لتكرار الإجراءات مرة أخرى، وتقديم طلب للخصم وانتظار رده من عدمه، خاصة إذا كان نظام التحكيم السعودي يلزم المحكمة بتعيين المحكم خلال مدة 
فـاذا مـا صدار قرار المحكمة بتعيين المحكم لا يجوز فيهه الطعن استقلالاً بـائي

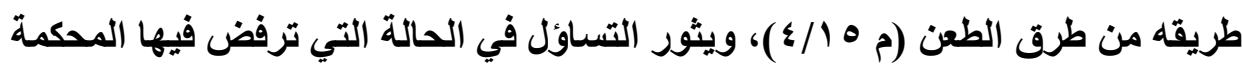
تعيين محكم، فهل يجوز الطعن على قرار المحكمة فى هذه الحالة؟؟.

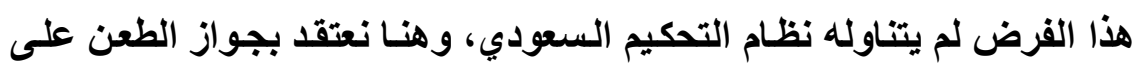

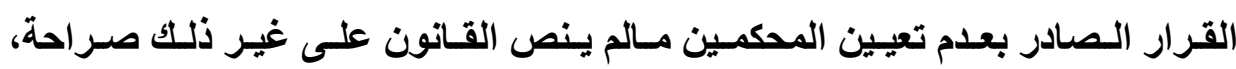

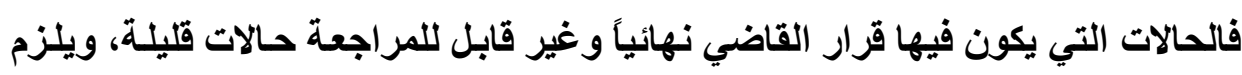

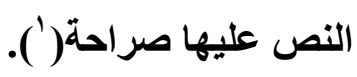

\section{المطاب الثاني \\ دور القضاء الوطني في رد المكمين وعزلهم واستبدالهم \\ أولاً : دور القضاء الوطني في رد المكمين:}

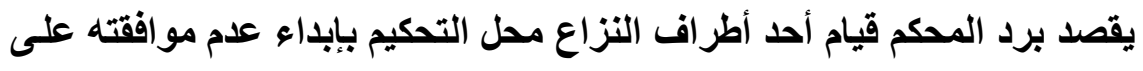

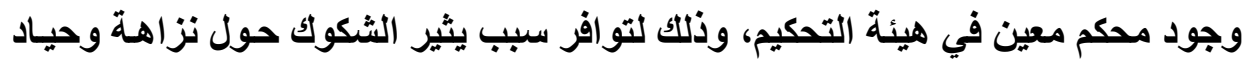

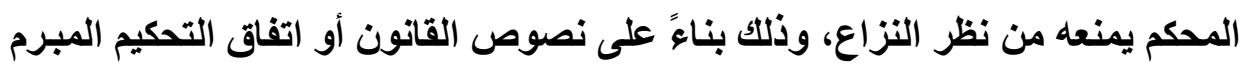

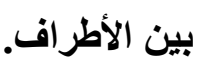

فأغلب التششريعات الوطنيـة تتضمن أحكامساً تتعلق بتتحيـة المحكمين الـذين يفتقرون إلى الثروط اللازم تو افرها فى المحكمين.

ونظام التحكيم السعودي بدوره يتناول في المادة (IV) مسألة تدخل القضاء في

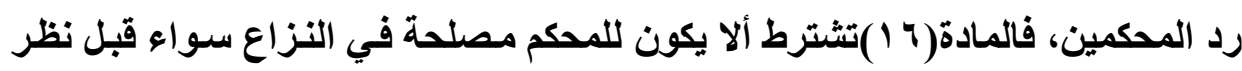
(1) أنظر، د. عبد الحميد الاحلب - موسوعة التحكيم _ التحكيم في البلان العربية ـ الكتاب الأول -

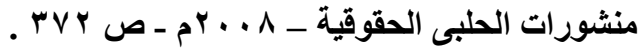


النزاع، أو أثناء سير عملية التحكيم، ما لم يكن قد أحساط الأطراف بذلك الأمر فبإذا كـان المحكم قد أحاط الأطراف علماً بما قد يثير الشكوك حول استقلاله، فلا يكون من حق الطرف الذي تم إعلامه وقبل بالمحم طلب رد هذا المحكم، ويعتبر هذا التصرف بمثابـة رضاء ضمني منه بالمحكم، ولا يجوز لله الاعتراض بعد ذلك بغية تعطيل سير إجراءات التحكيم (')، والالتزام بالإفصاح في هذه الحالة يقع على عاتق المحكم،وإلا أعتبر مخلاً بالتزامه بالحيدة والاستقلال () (r). كمــا يمنـع المحكم مـن نظر الــعوي بنـاء على ذات الأسـباب التـي يمنـع فيهـا القاضي من نظر الدعوي، وهو أمر كان النظام السعودي أكثر وضوحاً فيه من نظيره المصري، وذلك بالنص الصريح على منع نظر اللـعوي بنـاء على ذات الأسباب التي يمنع فيها القاضي المادة (7 Y/ م) من نظام التحكيم السعودي.

والحقيقـة أن هذا النص يعتريـه التنـاقض، والذى يظهر في صعوبة توفيق اعتبارات حياد المحكم بذات مفهوم حياد القاضس، ففي التحكيم يعين أطراف النزاع المحكمين، وهو ما يفترض معه وجود معرفة وثقة بين المحكم المختار والطرف الذي لئي

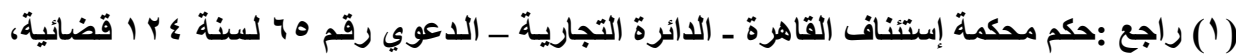

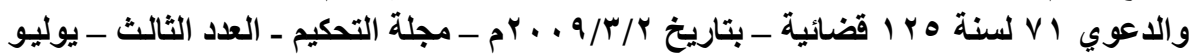

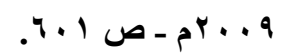

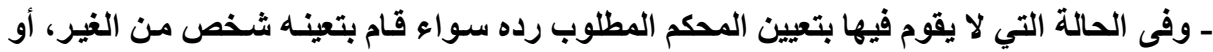

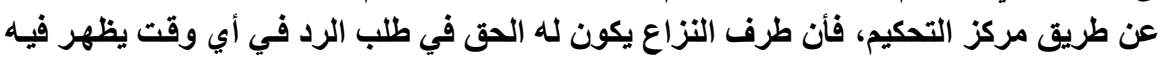

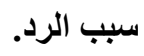

$$
\text { ـ أنظر: د. أحمد عبد الكريم سلامه ـ مرجع سابق ـ ص ه } 1 \text { ـ ــ }
$$

$$
\text { (ץ) راجع حكم محكمة النقض الفرنسية: }
$$

-Arrêt nº1568 du 19 décembre 2012 (10-27.474) - Cour de cassation Première chambre civile - ECLI:FR:CCASS:2012:C101568 www.courdecassation.fr. 
اختاره، وهو أمر يختلف تمامـاً عن مفهوم حياد القاضسي (')، فكان من الأحرى عدم النص على تماثل اعتبارات رد المحكم واعتبارات رد القاضي والواردة فى الماده ( • 9) من نظام المرافعات الشرعية السعودى، وذلك لاختلاف طبيعة عمل كل من القاضى المحكم، واختلاف فلسفة كل من النظامين .

وهو ما يتبناه المشرع المصرى فى المادة (1 1 ) من قانون التحكيم فنص على أنـه " لا يجـوز رد المحكم إلا إذا قامـت ظروف تثير الشكولك ... " ويتضح مـن هذه فئ المادة أنها لم تنص إلا على سبب عـام واحد، وبالتـالى جعلت حالات رد المحكم غير خاضـعة للحصر ، وأنهـا مسألة تقديريـة حسب كلل حالـة على حدة، تقدر ها محكمـة الموضوع، فقانون التحكيم المصرى لا يحيل على قانون المرافعات فيما ورد بثأن عدم صلاحية القضاة وردهم مكتفياً بـالظروف التى تثير شكوكاً جديـة حول حيدة المحكم واستقلاله، وبذلك عدل المشرع المصرى عمـا كانت تقرره المـادة (r م ه) الملفاه من قانون المرافعات التى كاتت تجيز رد المحكم لذات الأسباب التى يرد بها القاضى، بذلك لا يقبـل طلب الـرد إلا إذا اسـتند إلـى ظروف تثيـر شـكوكاً جديـة حول حيـدة المحكم

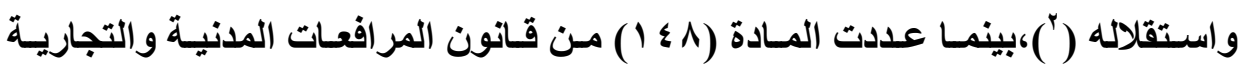
المصرى الحالات التى يجوز فيها رد القاضى.

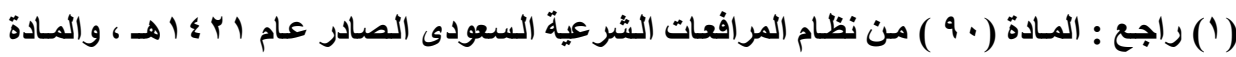

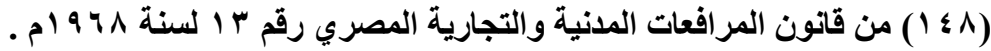

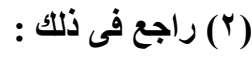

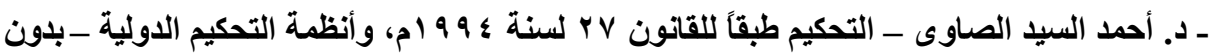

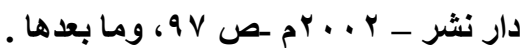

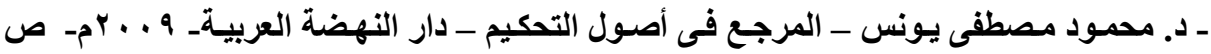

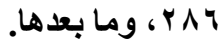
ـ د. فتحى والى - قانون التحكيم بين النظرية والتطبيق - منشأة المعارف - الاسكندريةـ V . . Y مـ-

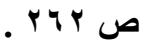


ويتلخل القضاء الوطني في رد المحكمين في الحالة التي لا يتحى فيها المحكم المطلوب رده أو إذا لميتم البت في الطلب المقدم لهيئة التحكيم خلال مدة حددها النظام بخمسة عشر يوم، فيجوز لطالب الرد أن يتقدم للمحمة المختصة طبقاً للمادة ( l/lV ) من نظام التحكيم السعودي، ويكون الحكم الصادر غير قابل للطعن بأي طريق من طرق

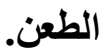

وفي الحالـة التـي يُرد فيهـا المحكم سـواء كـان ذلكت مـن قبـل هيئة التحكيم أو المحكمة يعتبر ما قد تم من إجراعات كأن لم يكن بما في ذلك حكم التحكيم ( م V V/ ع )، وهذا جزاء طبيعي في حالـة اختلال الشروط الـلازم توافرهـا في المحكمين، وحمايـة لحسن سير ونزاهة عملية التحكيم. وطبقـا للمسادة (1/1/1) من قانون التحكيم المصرى يقدم طلب الرد إلـي هيئة التحكيم مبيناً به الأسباب التي يبني عليها، فإذا لم يتتح المحكم المطلوب رده خلال مدة زمنية معينة تتولي المحكمة المختصة ـ سواء المحددة بالقانون، أو التي اتفق عليها

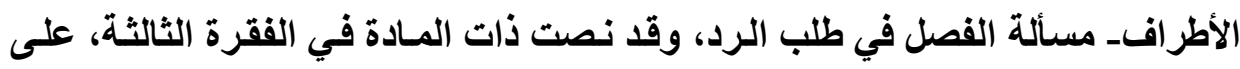
عدم توقف إجراءات التحكيم بناء على تقديم طلب الرد لحين الفصل فيه، ونري أن العلة من ذلك هي سد بـاب التحايل من إتخاذ طلبـات رد المحكمين وسيلة لوقف إجراءات (التحكيم('). (1)

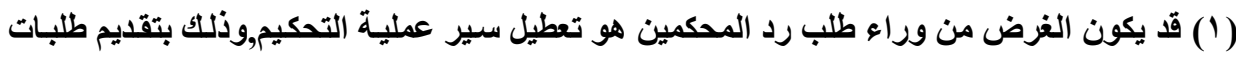

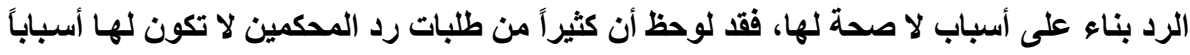
حقيقية تؤثر في نزاهة واستقلال المحكمين, وفي أغلب الأحيان يتم رفض أكثرها ولات ولا يقبل منها إلا لإن عدداً ضئيل جداً.

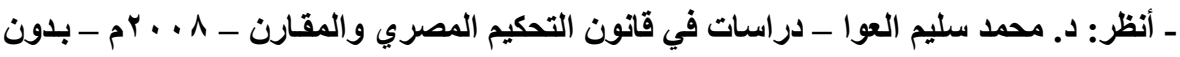

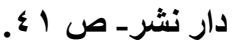


أما نظام التحكيم السعودي فيرتب على تقديم طلب الرد أمام هيئة التحكيم وقف الإجراءات،ولا يرتب ذلك في حالـة الطعن على قرار الهيئة فيطلب الرد (')، وهو مـا نري ضرورة التظلي عنه والنص على عدم توقف إجراءات التحكيم في كل الأحوال، حتي لا يتخذ هذا الإجراء وسيلة للمماطلة ووقف إجراءات التحكيم بغرض الإضرار بالطرف الأخر.

فإن كان خيار المنظم السعودي هو وقف إجراعات التحكيم نتيجة لتقديم طلبـات الرد، كان من الأحرى أن يحيط جدية الطلب بالضمانات الكافية، وذلك كأن يلزم الطرف الذى يقلم طلب الرد بمبلغ من النقود يوضع في خزينـة المحكمة يفقده في حالـة كون

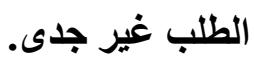

كما أن نظام التحكيم السعودي قد أغفل الأثار المترتبة على تقديم طلب الرد أمسام الجهات القضائية، وهل يترتب عليه وقف إجراعات التحكيم أم لا، والأحرى ألا تتوقف إجراءات التحكيم في هذه الحالة، حتى يتم الفصل في طلب الرد، مـع وضع الضمانـات الكافية لجدية الطلب، والعلة من ذلك هو تجنب الطلبات الكيدية، والتي يقصد من ورائها التعطيل والإضرار بالطرف الأخر خاصة في مجال العلاقات التجارية. وعموماً يجب على المحكم الأي يسند إليه مهمة التحكيم في أي نزاع أن يفصح عن أي صلة تربطه بـالأطراف المتنازعة ()، وكذلك إذا جد أي ظرف بعد تعيينه من شأنه أن يؤثر في حياتـه أو يثير الشبهات في استقلاله، وهذا مـا يتبنـاه أكثر المراكز

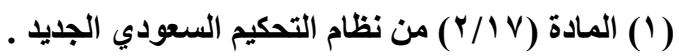

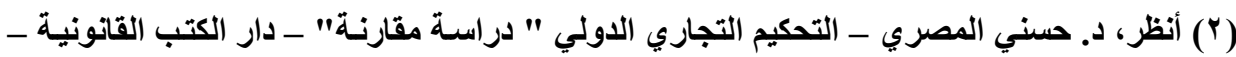

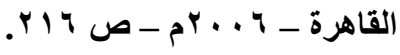


التحكيميـة والتشريعات الوطنيـة الخاصـة بـالتحكيم،والاتجـاه الفقهـي الغالب(') يـري بضرورة عدم التمسك بالحد الأقصى لحياد واستقلال المحكم، وذلك نظراً لأن المحكم الذي يعينه أحد أطراف النزاع يكون معروفاً بالنسبة لـه ومحل ثقته، لذا تأخذ بهذا الاتجاه أغلب مراكز التحكيم العالمية، وأحدث تشريعات التحكيم الوطنية،فمجرد تعيين المحكم من قبل أحد الأطراف لا يثير الشكوك حول استقلاله ونزاهته، وهو مـا أكدته محكمة النقض الفرنسية في أحكامها('). وفى كل الأحوال يجب على المحكمة التي تنظر طلب الرد المرفوع إليها من قبل أحد الأطر اف أن تتحرى الدقة في نظر الطلب المقدم لها، وأن يبنى على أسباب تمس نزاهة وحيدة المحكم المطلوب رده(")، تجنباً لسوء إستخدام هذه الوسيلة بقصد تعطيل

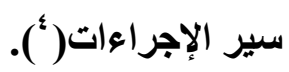

وهذا ما أكده القضاء السعودي في أحكامهـ حيث رفض طلب رد قدمتهـ المـدعى عليها بناء على ما جاء على لسان وكيلها أن هنـاك علاقة مهنية وشر اكة بين المحكم المختار ووكيل المدعى عليها، والطعن في ذلك لقيام شبهة تستوجب الرد، هذا وقد أقر وكيل المدعية بأنه لا توجد علاقة قائمسة توجب الرد بين المدعى عليها وبين محكمها

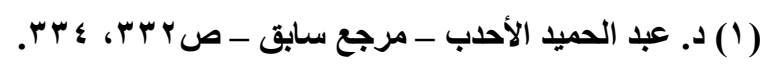

(2) Arrêt $n^{\circ} 962$ du 20 octobre 2010 (09-68.131) - Cour de cassation Première chambre civile - www.courdecassation.fr.

(3)Arrêt n 307 du 13 mars 2013 (12-20.573) - Cour de cassation - Première chambre civile - $\quad$ ECLI:FR:CCASS:2013:C100307 www.courdecassation.fr

(4) Gaillard - Les manoeuvres dilatoires..., op, cit., p. 766-768. 
المختار من قبلها، ولم يثثبت لدى المحكمة مـا يوجب رد المحكم المختـار(')، ونـرى أن هذا الحكم يبين الإختلاف في مفهوم حياد ونزاهة القاضي مقارنة بالمحكم . *ثانيًا: عزل المكمين واستبدالهم .

يكون عزل المُحكم بإحدى طريقتين: الأولى عن طريق إتفاق طرفي النزاع على العزل، ويعتبر عزل المحكم في هذه الحالـة تنفيذاً للإِرادة المشتركة لطرفي(ب) النزاع

$$
\text { والتي تعتبر شرطاً لصحة العزل ("). }
$$

فلم يعد من المقبول أن يقوم الطرف الذى قام يتعين محكم من طرفه أن يعزلـه بمنتهى الحرية، فالمحكم بمجرد أن يتم اختياره يصبح مستقلًا عن الطرف الذَى اختاره ويصبح هذا الطرف مجرد خصم في النزاع، لذا لا يمكن أن يقوم بعزله بإرادته المنفرة، إذ لابد من اتفاق طرفي النزاع على عزل أحد المحكمين، وذلك لأن الفكرة القائلة بكون المحكم وكيلاً عن المحتكم ويجوز لهذا الأخير عزلة بحرية قبل إصدار الحكم قد اندثرت

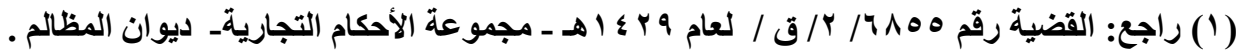

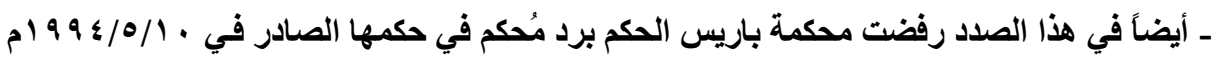

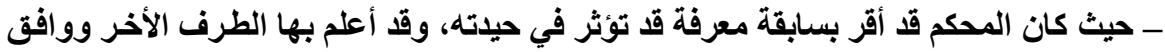

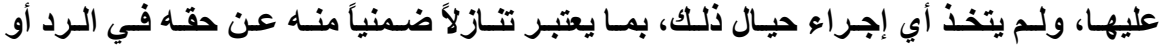

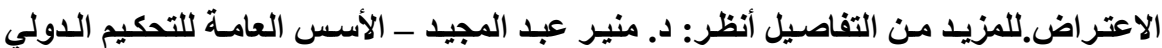

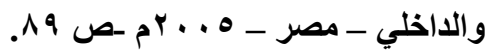

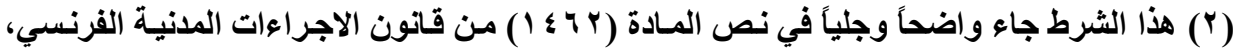

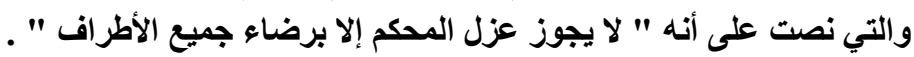


وتخلت عنها أغلب النظم القانونية، وميع ذلك يجوز عزل المحكم بناء على طلب أحد

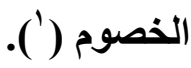

الثانية: اللجوء للقضاء في الحالة التي يتعذر على المحكم أداء مهمته، أو لم

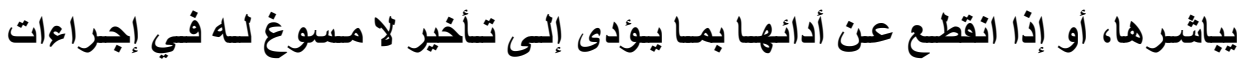

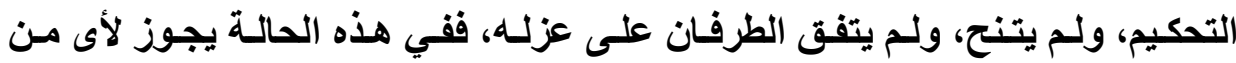

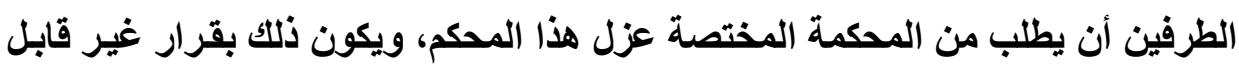
للطعن بأي طريق من طرق الطعن(م/1 من نظام التحكيم السعودي). فلا يكون اللجوء للمحكمة بدايـة لعزل المحكمين، وإنمـا ينبغي أولاً إستنفاذ

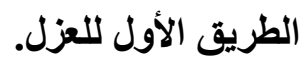
وهذه الوسيلة قد تستخدم لتعطيل إجراءات التحكيم مـن قبل أحد الأطراف للإضرار بالطرف الأخر ، لذا يتعين على المحكمة التي يرفع إليها طلب بعزل محكم أن تتحرى الدقة في قرارها. والعلة من تقرير حق عزل المحكم سواء بالاتفاق أو بنـاء على قرار صادر من

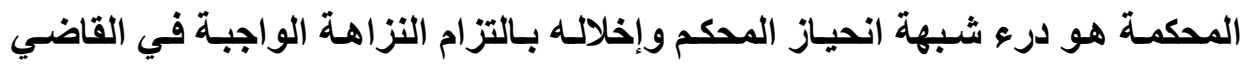
التحكيمي، ونعتقد أن المنظم السعودي كان عليه ألا يجيز طلب التعويض للمحكم في التي

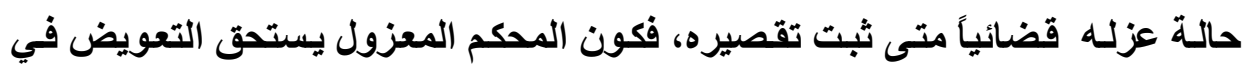
حالة عزله قضائياً يغنى بالضرورة صدور قرار المحكمة بغير أسباب جدية، وهو مـا يترتب عليه تناقض وإرباك لسبر عملية التحكيم من الناحية العملية.

(1) د. هشام خالد ـ تكوين المحكمة التحكيمية في مناز عات التجـارة الدولية ـ المجلد الأول ـ منشأة

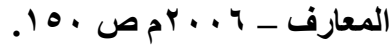


وفى أي من الحالات السابقة سواء حكم برد المحكم أو عزلهه، يجب إستبداله بأخر، كما لو كان المحكم واحداً ففي هذه الحالة يؤدى عدم استبدال المحكم المتحي أو المعزول أو الذى تم رده إلى توقف عملية التحكيم، وكذلك في الحالات التي تكون فيها هيئة التحكيم مشكلة من أكثر من محكم، فيجب الاستبدال تفادياً لحدوث اختلال في عدد المحكمين بمـا يـؤدى إلى عرقلة سير عمليـة التحكيم، هذا ولـم يتــاول نظـام التحكيم السعودي مسألة استبدال المحكم بأخر، ولا الإجراعات التي تتبع في ذلك. فباذذا عزل المحكم أو تم رده، أو توقف لأى سـبب كـان عن أداء مهمته، يثور التساؤل عن الألية المتبعة فى تعيين محكم بديل ؟ . نعتقد فى هذه الحالة بتمتع الأطراف بالحرية الكاملة في تعيين محكم بديل للذي إنتهت مهمته سواء بالاتفاق أو باللجوء إلى القضاء في حالة عدم الاتفاق، وذلك على

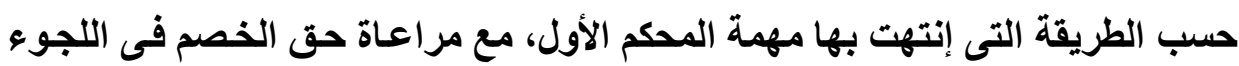

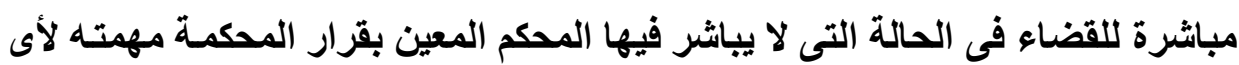




\section{الفصل الثاني}

دور القضاء الوطني في هرحلة سير إجراءات التمكيم

يكون دور القضاء الوطني ظاهراً وفعالاً في حالات التحكيم الحر والذى يكون فيه لكل من الطرفين كامل الحرية في تحديد شكل وتكوين هيئة التحكيم، وطريقة تعين

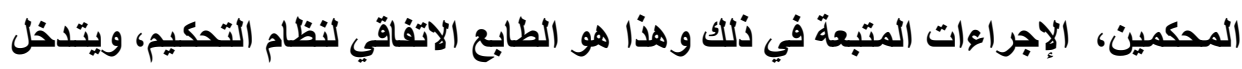

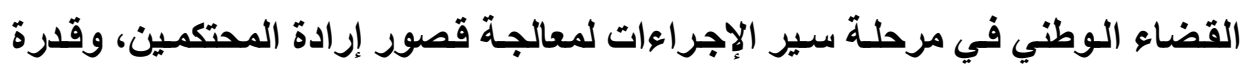

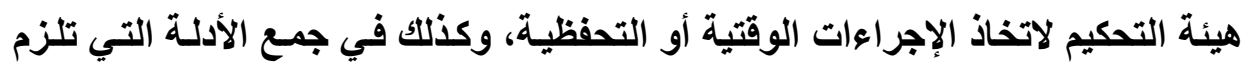

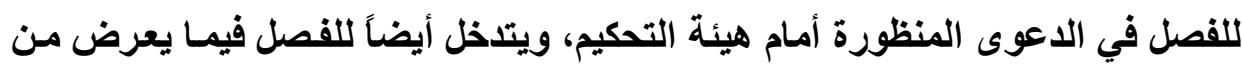

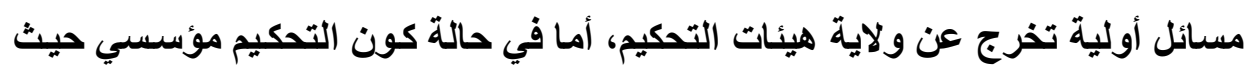

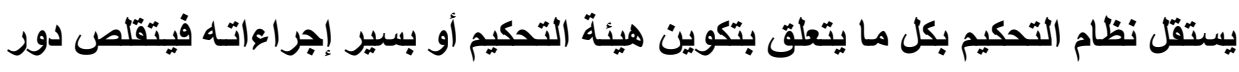

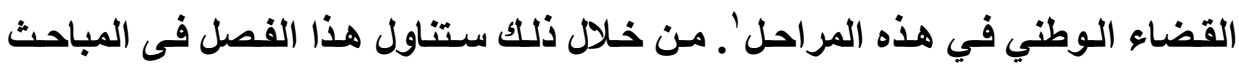

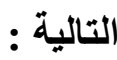

(1) P. Lalive -Avantages et inconvénients de l'arbitrage ad hoc -Etudesffertes à Pierre Bellet- Paris- 1991- p. 301. 


\section{المبحث الأول}

\section{دور القضاء الوطني في اتخاذ التدابير الوقتية والتحفظية}

التدابير الوقتيـة (')هي تلك التدابير التي تتخذ قبل انعقـاد الخصومة أو أثنـاء

السير فيها،وذلك للفصل في مسألة مستعجلة دون انتظار الحل النهائي، فهذا الإجراء لا يقصد به الفصل في موضوع النزاع،فهي حماية قضائية وقتية سابقة على صدور الحكم

$$
\text { المنهى للنزاع برمته( ). (ال). }
$$

أما التدبير التحفظي فُيتخذ بهاف المحافظة على حق أو عين لحين الفصل في

موضوع النزاع بشكل نهائي، ويقصد من وراء هذه الإجراءات ضمان فاعلية القرار

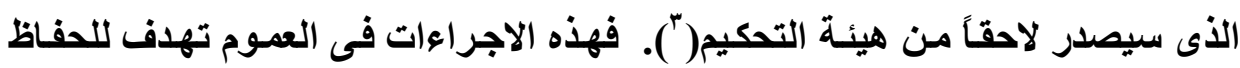

$$
\text { على المراكز القانونية أو الحقوق وأدلة الاثبات ( ). }
$$

ويعالج نظام التحكيم السعودي موضوع دور القضاء فى إتخـاذ التدابير الوقتية

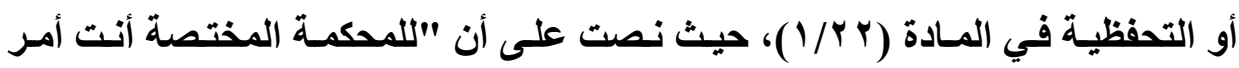
باتخـاذ تـدابير مؤقتـة، أو تحفظيـة بنـاءً على طلب أحد طرفي التحكيم قبل البدء في (1) أنظر: د.خالد محمد القاضسي - موسـوعة التحكيم التجـاري الدولي ـ دار الشروق - القـاهرة-

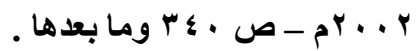

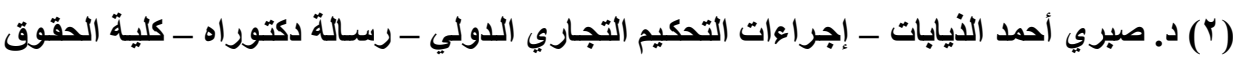

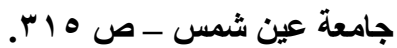

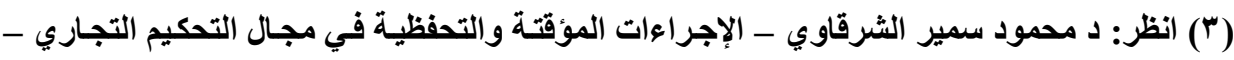

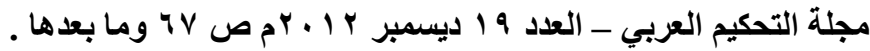

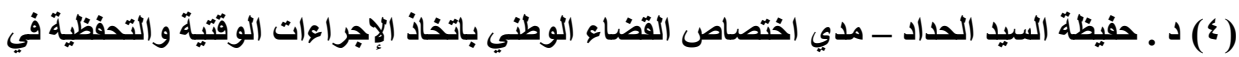

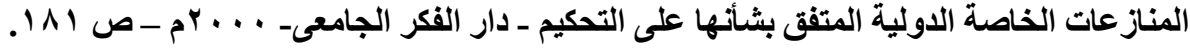


إجـراعات التحكيم، أوبنـاءً على طلب هيئة التحكيم أثنـاء سـير إجـراءات التحكيم، ويجوز الرجوع عن تلك الإجراءات بالطريقة نفسها، مـالم يتفق طرفا التحكيم على خلاف ذلك ".

فـور القاضـي الـوطني فـي اتخــاذ هـذه الإجـراعات لا يقــي دور المُحكـم في اتخاذها إنما تتشارك كل من هيئة التحكيم والمحساكم الوطنيـة في حفظ حق أو مـال، أو اتخاذ إجراء وقتي بغية الإبقاء عليه لحين الفصل في الدعوي(')، وذلك في حالـة عدم تنفيذ أحـد الأطراف لهـذا الإجراء طواعيـة، فاتخـاذ هذه الإجراءات مـن قبـل القضاء الوطني يتوقف على مدي تعاون طرفي النزاع من عدمـه، وفي كل الأحوال لا يتطرق القاضي الوطني من خلال الإجراءات الوقتية أو التحفظية إلي حل موضوع النزاع وإنمسا يقتصر الأمر على اتخاذ إجراءات وقتية وتحفظية مستعجلة .

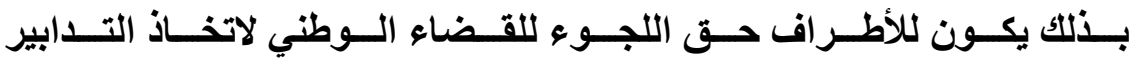
الوقتية والتحفظية قبل البدع في إجراعات التحكيم،( مرحلة انعقـاد الخصومة)،ولهيئة التحكيم طلب اتخـاذ تلك التدابير أثنـاء سير الدعوى،ولعل الحكمـة من منح الأطراف في النزاع حق اللجوء للقضاء قبل بدء سير الاجراءات هو عدم كون هيئة التحكيم منعقدة.

كذلك المشرع المصري في المسادة (ع ا ) مس القـانون رقم VY لسنة ؛ 99 ام نص على أن " يجوز للمحكمة المشار إليها في المـادة (9) مـن هذا القانون أن تـأمر

(1) J. Robert, L'arbitrage, droit interne et droit international privé, 6e éd.,Paris, 1993, p. 272.

- M. de Boisséson, Le droit français de l'arbitrageinterne et international, 2e éd., Paris, 1990, p. 759. 
بناء على طلب أحد طرفي التحكيم باتخاذ تدابير مؤقتة أو تحفظية سواء قبل البدء في إجراءات التحكيم أو أثناء سيرهاיو.

وهذا التدخل في العموم يمس حق الأطراف في اللجوء إلي التحكيم أو يعتبر تنازلا عنه، فيثبت الحق لهيئة التحكيم الفصل في موضوع النزاع(')، وأن كل مـا يقوم به القضاء في هذه الحالة هو المساعدة في حسن سير عملية التحكيم من خلال إتخاذ تدبير وقتى أو تحفظى دون المساس بموضوع النزاع، وإلا أعتبر تدخلاً يمس باستقلال التحكيم • والمشرع الفرنسي في قانون الإجراءات المدنية يمنح هذا الحق لقاضسي الأمور المستعجلة بناء على طلب هيئة التحكيم، أو أحد أطراف النزاع شريطة أن تتوافر حالة الاستعجال، وذلك في المسادة (9 ـ / (1)، ولو كان هذا الإجراء يتم أثناء سير التحكيم دون أن يتعارض ذلك مع سير التحكيم.

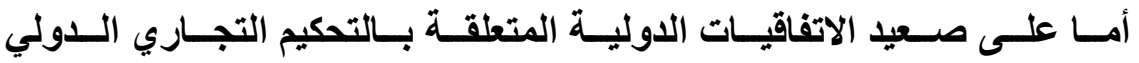

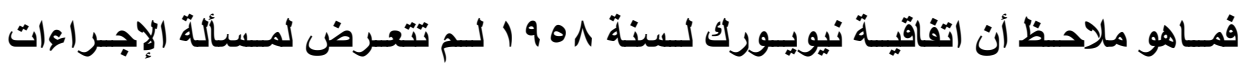
الوقتية والتحفظية، على خلاف المادة(9 + ) من القانون النموذجي للتحكيم والتي نصت على أن " يجوز للمحكمة بنـاء على طلب أحد الأطراف أن تأمر باتخـاذ أي إجراعت

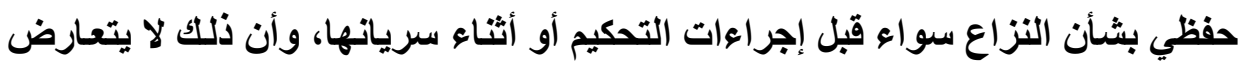

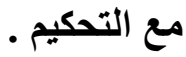

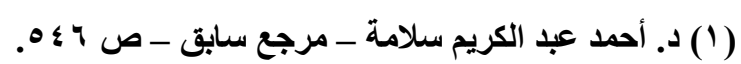

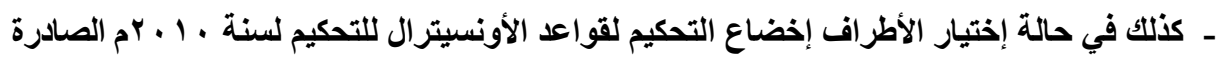

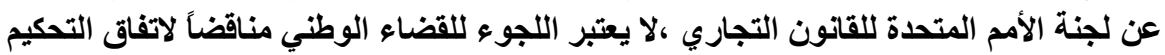

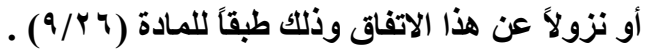


وكذلك المادة (^/ه ) من نظام تحكيم غرفة التجارة الدولية بباريس والتي تنص على أنـه يجـوز للأطراف قبل تسليم المحكم ملف الـدعوي أو أثنــاء سـير الخصومة التحكيمية أن يطلبا إلي أي سلطة قضائية اتخاذ تدابير مؤقته أو تحفظية دون أن يشكل هذا الطلب مخالفة لاتفاق التحكيم('). وهذا التدخل من جانب القضاء في سير عملية التحكيم يعتبر إجراء استثنائي لا

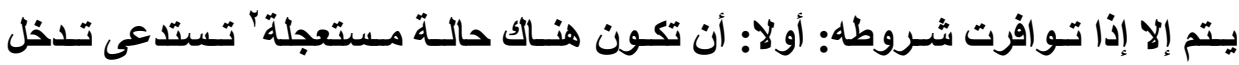
القضاء،سواء قبل انعقاد هيئة التحكيم أو بعد انعقادهـا، وهذا التدخل بعد تشكيل هيئة التحكيم إنمـا يكون بقصد مساعدتها في تلافى مـا قد يشوب سير عملية التحكيم من قصور عن طريـق اتخـاذ تـدابير وقتيـة وتحفظيـة بصورة مستعجلة، ولا يعتبر تـلخل القضاء هنا مبدأ عام جائز في كل وقت،فهذا القول يمس باستقلال التحكيم عن القضاء، بل لابد من وجود ما يبرره.

ثانيا: يجب ألا يترتب على اتخاذ هذه الإجراءات مساساً بأصل الحق و إلا وجب على المحكمة أن تقضى بعدم جواز نظر الاعوى. وهذه الشروط لازمة من أجل إتخاذ المحاكم الوطنية أي إجراء وقتي أو تحفظي سواء تقدم بهذا الطلب أحد أطراف النزاع، أو كـان الطلب مقدماً مـن هيئة التحكيم نفسها، وعلى المحكمة أن تفصل في مدي جدية هذا الطلب وكونـهـ مستعجلاً، ولا يمس بموضوع التزاع .

$$
\begin{aligned}
& \text { (1) للمزيد أنظر: د. حسني المصري - مرجع سابق - ص rه ب وما بعدها . }
\end{aligned}
$$

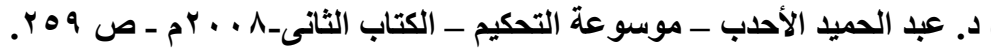


وهذه الإجراءات تتذذ من قبل المحكة التي يحددها الأطراف طبقاً لاتفاق التحكيم، وإذا

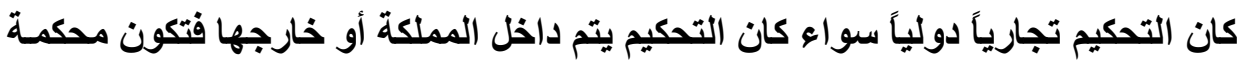
استئناف الرياض هي المختصة، مالم يتفق الأطراف على اختصاص محكمة استئناف أخري( م ^/ Y من نظام التحكيم السعودي). 


\section{المبحث الثاني}

\section{هساعدة القضاء الوطني هيئة التمكيم في جمع الأدلة}

الأصل أن مهمـة جـع الأدلـة في النزاعـات المعروضـة على التحكيم تكون من

اختصاص هيئات التحكيم،إلا أن القضاء الوطني يطلب منه أحيانـاً القيام بذلك في حالة عدم قرة هيئة التحكيم على تتفيذ مهامها.

فقد يتطلب أداء المحكم لمهمتـه سـلطة لا تتـوافر إلا للجهـات القضائية لجمـع الأدلة الخاصة بالنزاع'، فالدلائل المكتوبة مثلاً لا يستطيع المحكم في أغلب التشريعات

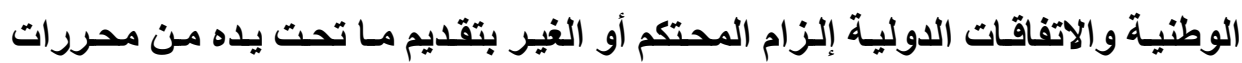
مكتوبة،ومعالجة لهذا القصور أجاز نظام التحكيم السعودي لهيئة التحكيم أن تطلب من الجهة المعنية مساعدتها في إجراءات التحكيم وفق مـا تراه هذه الهيئة مناسباً لحسن سير التحكيم (م Y Y M/ (Y).

فيكون اللجوء للسلطات القضائية بشكل استثنائي في حالة عجز هيئة التحكيم

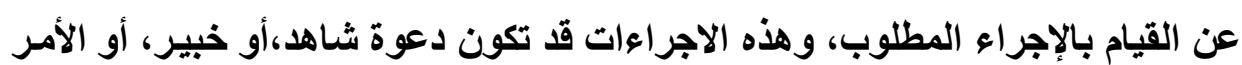
باحضار مستتد أو صورة منـه، أو طلب الإنابة القضائية، وسنتناول ذلك على النحو

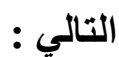

(1) أنظر: د. محمد الجمـال، و د. عكاثـة محمد عبد العال - التحكيم في العلاقـات الخاصـة الدولية

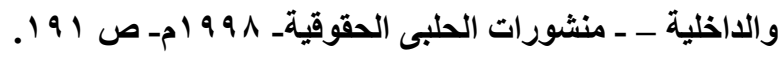


قد يكون الشهود الـذين تَلـزم شـهادتهم أمسام هيئسة التحكيم مـن الغير، وتكون الأقوال التي يالون بها على قدر من الأهمية تساعد على الفصل في النزاع المعروض

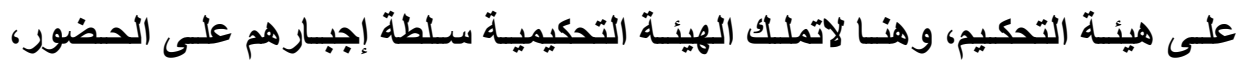
والإدلاء بـأقو الهم،وذلك على أسساس أن التحكيم يقوم على اتفـاق الأطراف، ولا تملك هيئة التحكيم إلزام أي شـضص بـالمثول أمامهـا لـم يكن طرفاً في الاتفـاق(')، فمـا مـن طريق إلا اللجوء للقضاء من أجل تحقيق ذلك، وهنا يقتصر دور القضاء الوطني على إصدار الأمر إلى الشاهد المطلوب بالحضور أمام هيئة التحكيم والإدلاء بأقوالهه، وتوقع المحكمة الجزاء القانوني علي الشاهد في حالة تخلفه عن الحضور، وهذا القول يؤيده

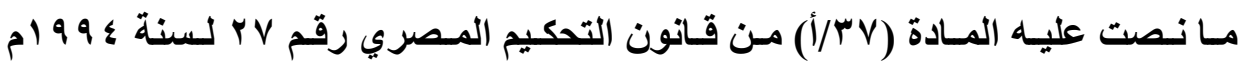
حيث نصت على أن يختص رئيس المحكمة المشار إليها في المادة (9) من هذا القانون بنـاء على طلب هيئسة التحكيم بمـا يـأتي : أـ الحكم على مـن يتخلـف مـن السهود عن الحضور أو يمتنع عن الإجابة بالجزاعات المنصوص عليها في المـادتين ^ V و ـ ^ مـن قـانون الاثبـات المـواد المدنيـة والتجاريـة"، فـلا يقصر قـانون التحكيم المـصري العقاب على من يتخلف عن الحضور، بـل يمتــ ذلك للشـاهد الذى يحضر ويمتنع عن

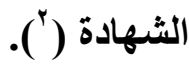

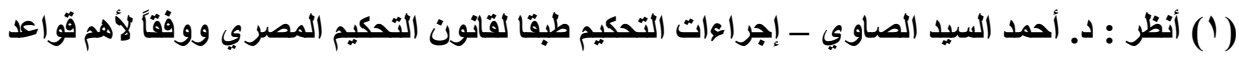

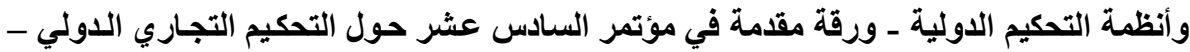

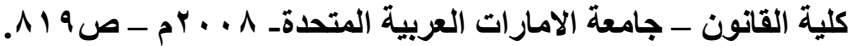

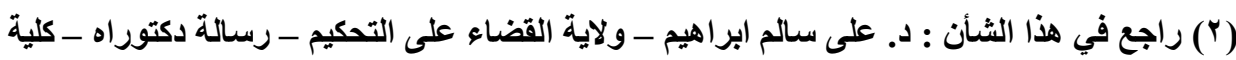

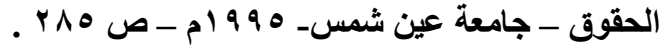


أما نظام التحكيم السعودي فقد أجـاز لهيئة التحكيم أن تطلب مساعدة الجهات المعنية بما تراه مناسبا لحسن سير التحكيم، ومن ذلك شهادة الشهود( م Y Y Y Y)، ومـع ذلـك فقد خـلا النظـام مسن أي إثـارة لتوقيع العقوبـة على الشـاهد الــى يتخلف عن الحضور، أو الذى يحضر ويمتنع عن الشهادة، وكذلك نظام المرافعات الشرعية من توقيع أى عقوبة على الشاهد الذى يأبى الحضور للإدلاء بشهادته ('). ثانيًاً : الدلائل الكتابية يعد الاليل الكتابي وخاصة في مجال التحكيم التجاري من أهم الأدلة التي تلجأ إليها هيئة التحكيم للفصل في النزاع المعروض ( (Y)، فقد يعزف أحد الخصوم عن تقديم ما تحت يده من مستتدات، فهل تملك هيئة التحكيم حق اللجوء للقضاء من أجل إصدار الأمر بتقديم ما تحت يا الخصم من دلائل كتابية؟؟ في الواقع لن تـتمكن هيئة التحكيم من إلزام الأطراف، ولا الشهود بتقديم مـا للايهم مس مستتدات،فعلدم تمتع هذه الهيئات بسلطة الإجبار يمنعها من تحقيق هذه الغاية، فما من طريق إلا اللجوء للمحاكم الوطنية للحصول على هذه الوثائق فى حالة عزوف الأطراف، وذلك من أجل إصدار حكم عـادل في النزاع المعروض (ّ)، وهو مـا قرره نظـام التحكيم السعودي (م Y Y/Y)، حيث أجـازت لهيئة التحكيم أن تطلب مـن

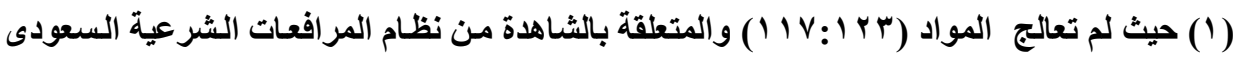

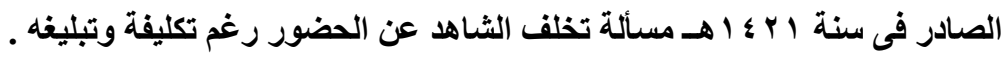
(r) د. هاى عبد الرحمن - دور المحكم في خصومة التحكيم وحدود سلطاته ـ دار النهضة العربية ـ

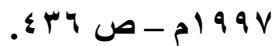

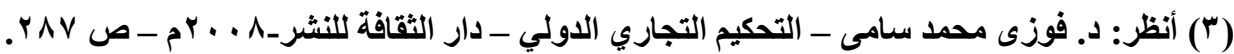


الجهـات المعنيـة مسساعدتها فـي إتخــاذ الاجـراعات التـي تراهـا مناسـبة، ومسن هـــه الإجراءات الأمر بإحضار مستتد أو صورة منه' .

ولم يعالج نظام التحكيم السعودى، ونظيره المصري حالة طلب أحد الأطر اف من القضاء إلزام خصمه بتقديم دليل أو مستند تحت يده، ونعتقد في هذه الحالة بجواز اللجوء للقضاء، فعدم تمتع الهيئات التحكيمية بسلطة الأمر يجعلها في حاجـة دائمـة إلى القضاء، ويتبع فى ذلك القواعدة العامة الواردة فى هذا الشأن، فاذا رفض الخصم تقديم مالديه من مستندات (†) كان على هيئة التحكيم أن تسلم بطلبات المدعى (").

(1) جلير بالذكر أن اللانحة التنفيذية لنظام التحكيم السعودى الملفى الصادرة فى ه ه ـ ؛ أهـ، والذئى حل

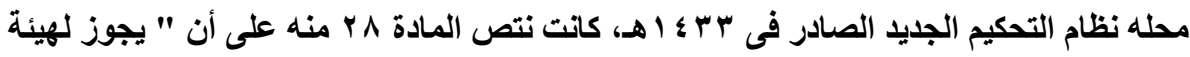

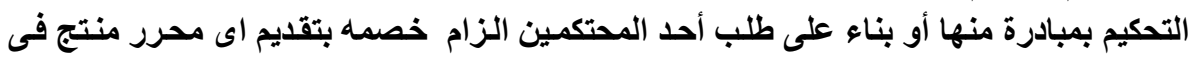

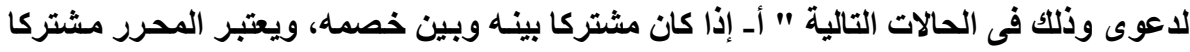

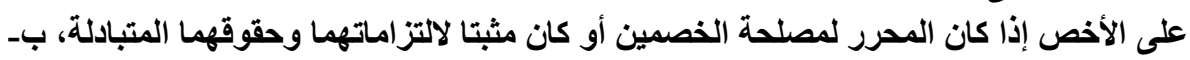

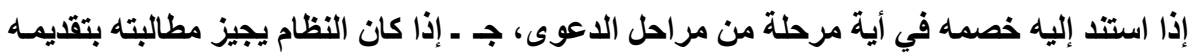

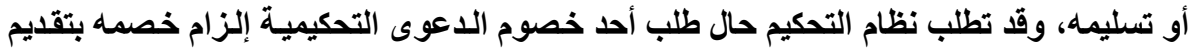

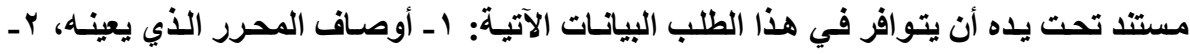

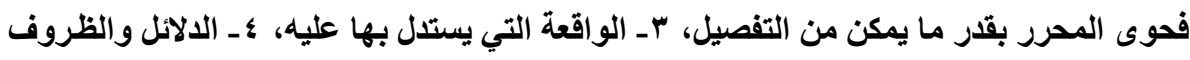

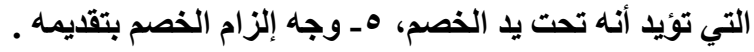

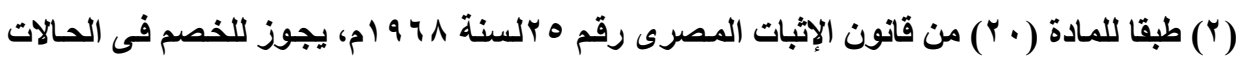

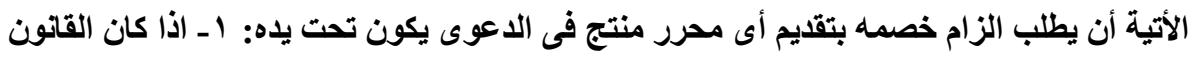

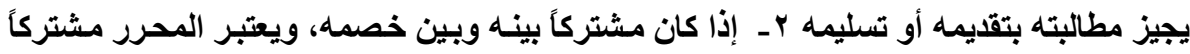

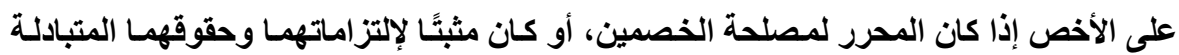

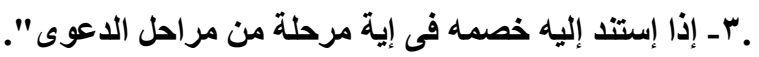

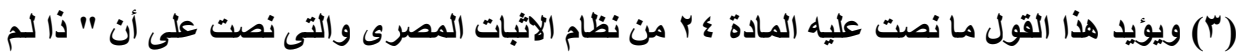

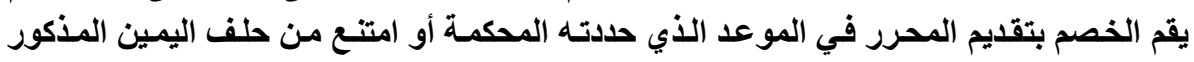

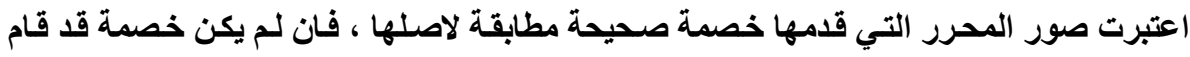

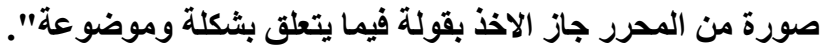




\section{ثالثًا :الإنابة القضائية.}

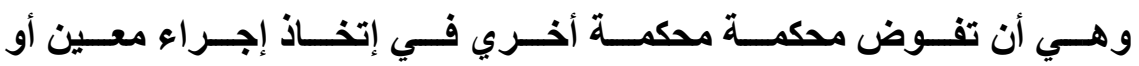

بعض الإجراءات، وذلك في دائرة إختصاصها، والتي يقتضيها الفصل في الدعوي المرفوعة أمامها، وذلك نتيجة لأي مـانع يعيق إتخـاذ هذه الإجراعات مـن قبل المحكمة

ولا يجوز لهيئة التحكيم أن تأمر بالإنابة القضائية بطريقة مباشرة، ولا يمكنها أن تتيب عنها محكمة أخرى للقيام بـإجراء قضائي معين، ولكن يتعين عليها أن تطلب من المحكمة المختصة إصدار قرار بالإنابة إلى محكمة أخرى،وهو ما يمثل تعاونـاً كبيراً بين الجهات المختصة في إنجـاز العدالـة وإنهاء النزاعـات التـي تطرح على هيئـات التحكيم (†)، ونظام التحكيم السعودي يتـاول مساعدة القضاء للهيئات التحكيمية في

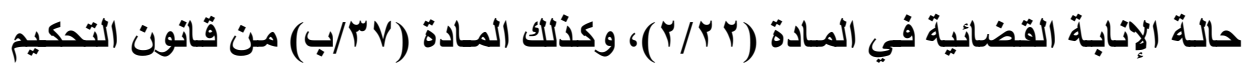
المـصرى حيـ أجـازت المحكمة المختصةـ وهـى المحكمـة المسشار إليهـا فـى المسادة

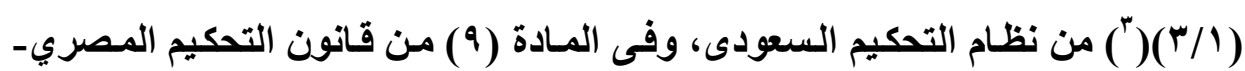
بناءً على طلب هيئة التحكيم الأمر بالإنابة القضائية،

(1) للمزيد من التفاصيل حول الإنابة القضائية راجع : د عكاثة عبد العال ـ الإنابة القضائية في نطاق

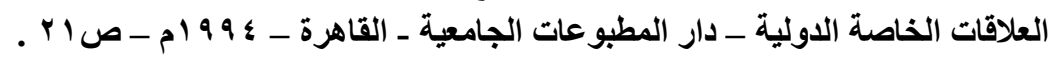

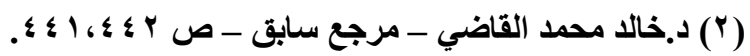

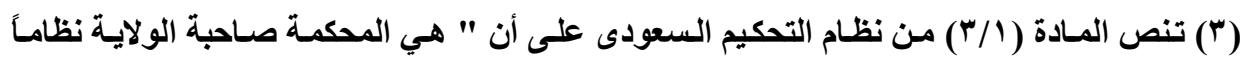
بالفصل في المنازعات التي اتفق على التحكيم فيها"، 
ولما كانت المحكمة المختصة هى التى تصدر الأمر بالإنابة القضائية، فيتبع بذلك

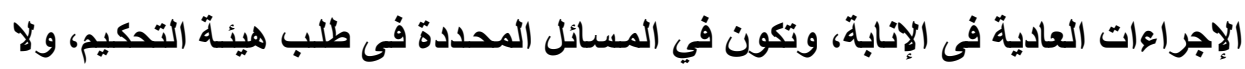
يجوز تجاوز ها('). ولم يحدد المنظم السعودي الحالات التي يجوز فيها للمحكمة المختصة الأمر بالإنابة القضائية على سبيل الحصر، حيث أجاز لهيئة التحكيم أن تطلب من المحكمة المختصة الأمر بالإنابة القضائية دون تحديد،إضـافة الى أن نظام التحكيم السعودى

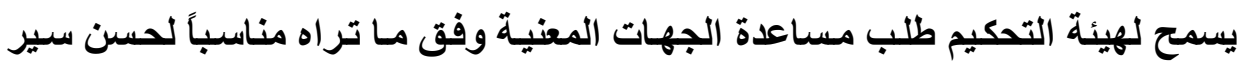

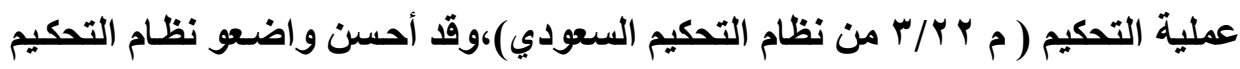
السعودي صنعاً بالنص على الإنابة القضائية فى مجال التحكيم، والاستعانة بالمحاكم السعودية لمساعدة هيئة التحكيم في الإجراءات التي قد تعجز عنها الهيئات التحكيمية،

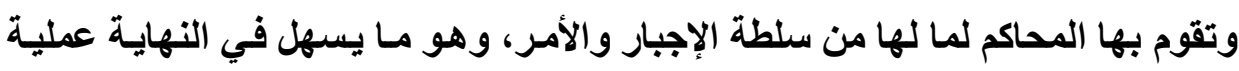
التحكيم ويحقق الأهداف المرجوة من نظام التحكيم عموماً.

(1) أنظر: د. رضا السيد عبد الحميد ـ مسائل في التحكيم _ دار النهضة العربية ـ ب . ب م-ص ص 


\section{المبحث الثالث}

\section{دور القضاء الوطني فى الفصل في المسائل الأولية}

المسائل الأوليـة تخرج غالبـاً عن ولايـة المحكم، وتكون مسائل غير مشمولة بإتفاق التحكيم أو يحظر التحكيم فيها كالمسائل الجنائية وغيرها من الأمسور التي تتعلق بالنظام العام(')، وقد نصت المادة (Y) من نظام التحكيم السعودى على عدم سريان هذا

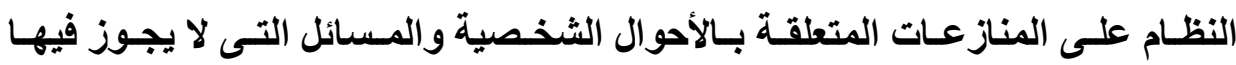

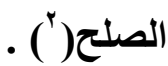

فقد تثار مسألة أولية بحيث يتوقف الفصل في اللاعوي على الفصل في هذه المسألة سـواء بقبول اللدعوي أو رفضها، كمـا قد تكون خارجة عن إختصاص هيئة التحكيم، ويجب أن تقرر هيئة التحكيم أن الفصل في هذه المسألة لازم للفصل في النزاع المعروض عليها(")، وأن تقرر أيضاً أن هذه المسائل تخرج عن ولايتها. ولما كانت هذه المسائل تقتضى بطبيعتها العرض على القضاء الوطني للفصل فيهـا بحكم يحـوز قوة الشيء المقضي فيـه(")، فمـن الـلازم اللجوع للقضاء الـوطني للفصل فيها، وفى هذا تقضى المادة (rv) من نظام التحكيم السعودي بأنـه"إذا عرضت

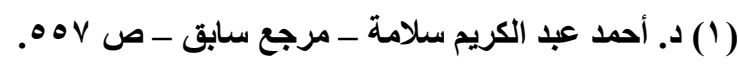

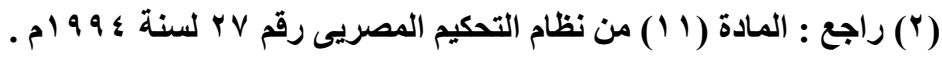

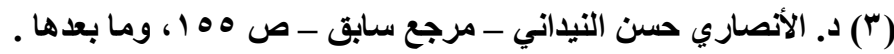

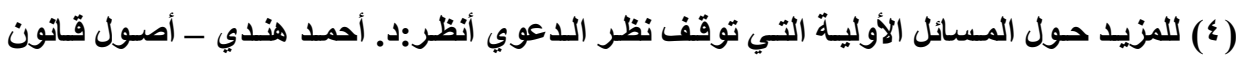

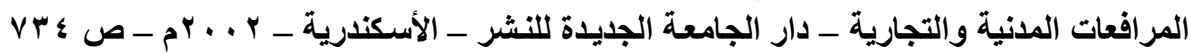




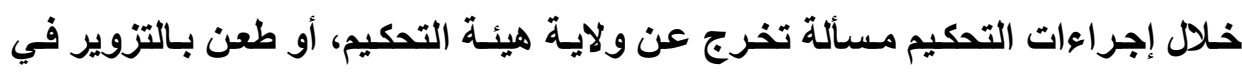

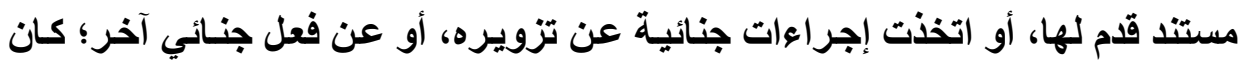

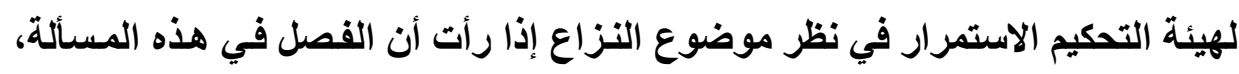

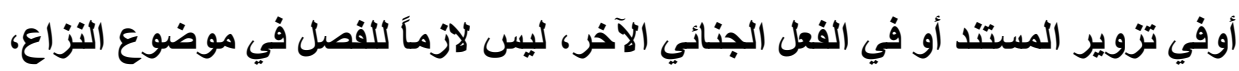

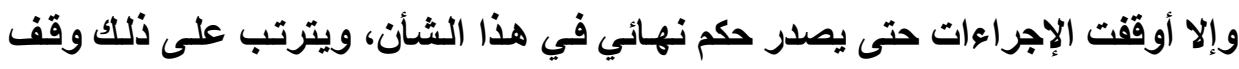
سريان الميعاد المحدد لإصدار حكم التحكيم ".

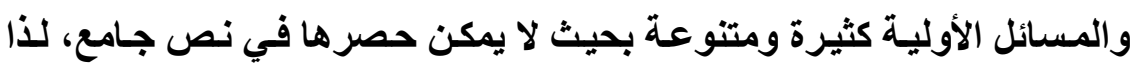
نلاحظ أن نظام التحكيم السعودي ينص على عدد من الحالات على سبيل المثال وليس

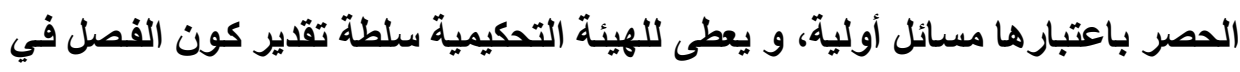

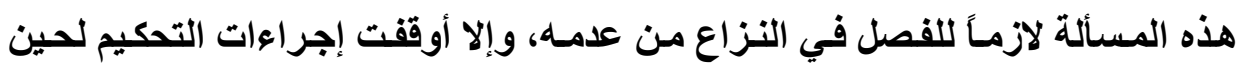

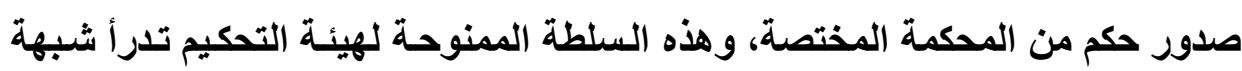

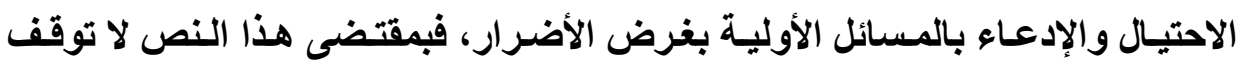

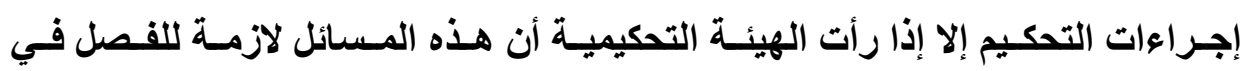
النزاع،وبناء على ذلك تقرر وقف إجراءات التحكيم لحين صدور حكم من السلطات التهات

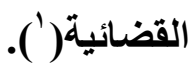

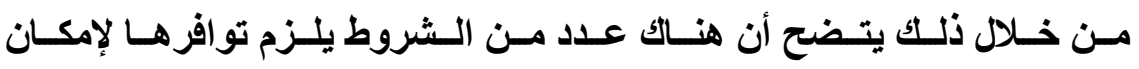

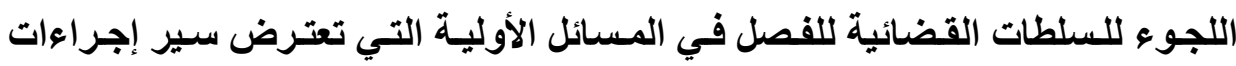

(1) (1) (1) (اجع حكم محكمة النقض الفرنسية

- Arrêt $n^{\circ} 1389$ du 25 octobre 2005Cour de cassation - Première chambre civile-www.courdecassation.fr 
أولا: يجب أن تثار أي من المسائل الأولية بخصوص الدعوي المعروض على التحكيم، ولا يمكن الفصل في الـدعوى بـالرفض أو القبـول إلا بعد الفصل في هذه

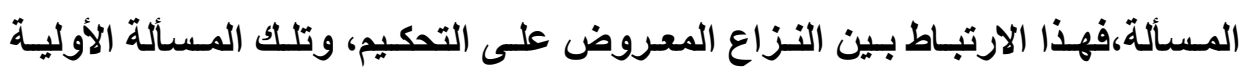
هو السبب الذى يمكن على أساسـه اللجوء للقضاء الوطني من أجل الفصل في هذه ('). ( المسألة

ثانيًاً : أن تقرر هيئة التحكيم أن الفصل في هذه المسألة لازم للفصل في النزاع،

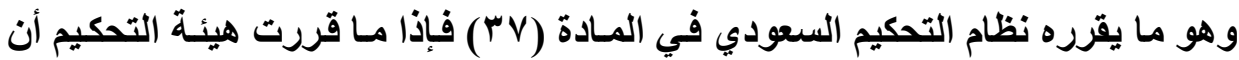
هذه المسالة الأوليسة لازمـة للفصل في الـاعوى وتخرج عن إختصاصها تحيل الأمر للقضاء، وتوقف إجراعات التحكيم لحين الفصل فيها،ويترتب على ذلك وقف سريان الميعاد المحدد لإصدار الحكم في المنازعة التحكيمية (†) (r). ويذلك تملك الهيئة التحكيمية وليس أطراف النزاع حق طلب الفصل فى المسائل الأولية التى تعترض سبر إجراءات التحكيم، فليس للخصوم اللجوء للقضاء فى هذه الحالة، وذلك طبقاً لصريح نص المادة (rv) من النظام . فباذا توافرت هذه الشروط جـاز اللجوء للقضاء الـوطني،ويتم وقف إجراءات التحكيم لحين الفصل في هذه المسألة، ولا يجوز للأطراف أن يتفقوا على إختصاص هيئة التحكيم بالفصل فى المسائل الأولية، فهذا الاتفاق يعتبر باطلاً ولا أثر لـه لمخالفته

$$
\text { للنظام العام ("). }
$$

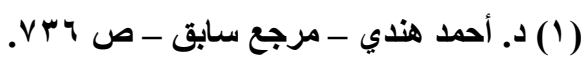

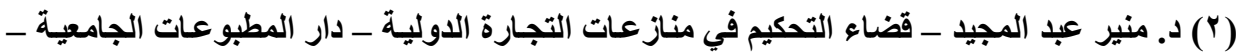

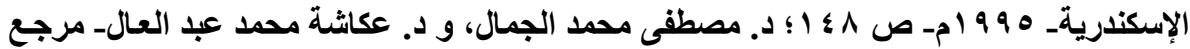

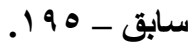

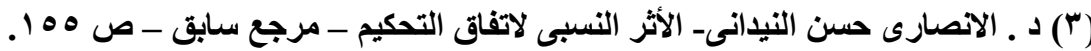


كمـا قد يتـلـل القضاء الوطني للفصل في بعض الأمسور الأخرى أثنـاء سير إجراءات التحكيم كتحديد مدة إضافية للفصل في النزاع التحكيمي، أو إصدار أمر بإنهاء

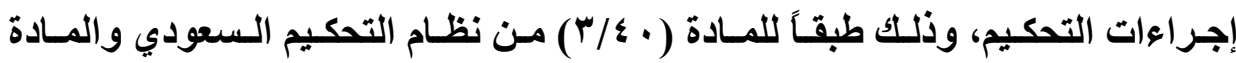

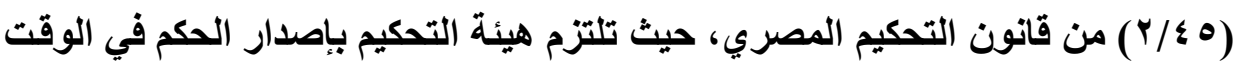
المتفق عليه من قبل الأطراف وفي الحالة التي لا يتم الاتفاق على موعد محدد تكون

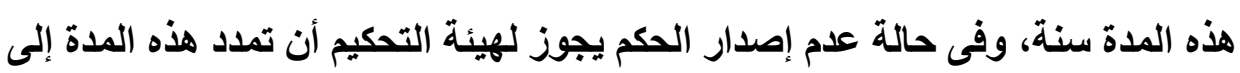

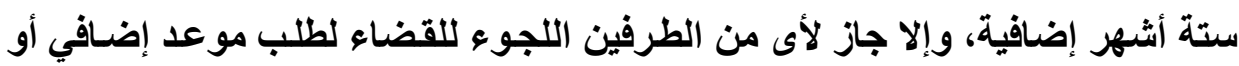

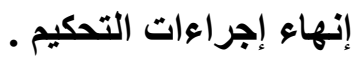


من خلال البحث في موضوع دور القضاء الوطني في تسيير إجراءات التحكيم سواء فى مرحلة انعقاد الخصومة التحكيمية، أو فى مرحلة سير إجراءات التحكيم فى النظام السعودى وبعض التشريعات المقارنة، توصلنا لعدد من النتائج والتوصيات، ولعل أهم هذه النتائج هى :-

أولاً: أن نظام التحكيم السعودى ييسر لهيئـات التحكيم القيام بعملها من خلال طلب مساعدة الجهات القضائية بالقدر الذى لا يمس استقلال التحكيم عن القضاء الوطنى.

ثانيًاً : أن مرحلة سير اجراعات التحكيم على درجة كبيرة من الأهمية، حيث تعتبر الأسـاس الذى تبنى عليه عملية التحكيم، لذا نجده محاطاً بقدر كبير من الأهمية من قبل المنظم السعودى، وهو ما يتضح من خلال نصوص مواد النظام . ثالثًا: أن الأصل فى تسيير إجراعات التحكيم وخاصـة في جمع الأدلـة واتخـاذ الاجراءات الوقتيـة والتحفظيـة يكون مـن إختصاص هيئة التحكيم، وتـذخل القضاء لا يكون إلا على سبيل الإستثناء، فلا يكون القضاء بديلاً فى هذه الحالات عن هيئة التحكيم إنما مساعداً لها فقط.

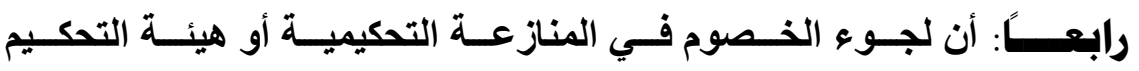
للجهات القضائية لا يعد تنـازلاً عن التحكيم، وإنمـا يكون بغرض المساعدة فى إتمـام إجر اع|ته نظراً لطبيعة التحكيم، وحاجته الدائمسة للقضاء بمـا لايـه من سـلطة الإجبـار والأمر . 


\section{وعلى ضوء ها تقدم فإننا نقترح بعض التوصيات}

أولاً : كان على المنطم السعودي أن ينص على إختصاص المحاكم الوطنية بنظر

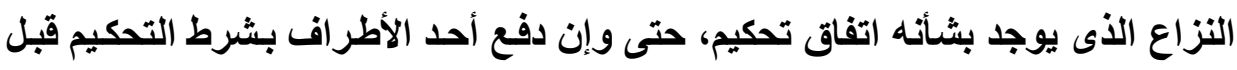
إبداء أي طلب أو دفع في الاعوى، وذلك في الحالات التي يكون فيها اتفلق التحكيم باطلاً أو لاغيا أو غير قابل للتنفيذ .

ثانيًا:يرتب نظام التحكيم السعودي على تقديم طلب الرد إلى هيئة التحكيم وقف

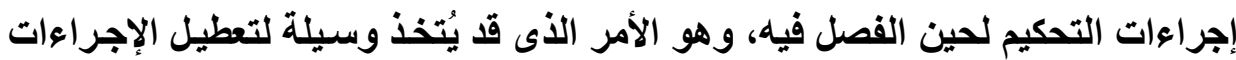
والمماطلة بقصد الإضرار بالطرف الأخر، كما أن المنظم السعودي قد أغفل أثر تقديم

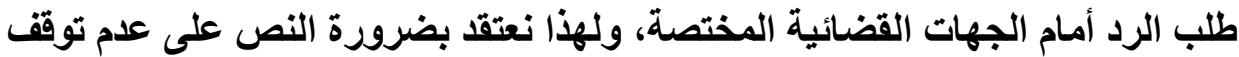

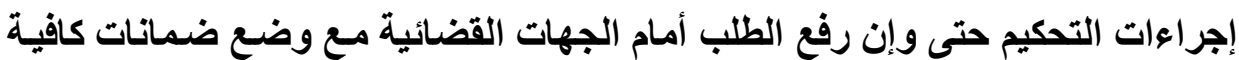

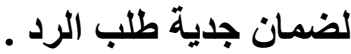

ثالثًا: كان على المنظم السعودي أن يشترط لعزل المحكم وجود أسباب جدية يينى عليها العزل حتى لا يكون من حق المُحكم المعزول أن يطالب بالتعويض لعزله بدون مبرر، مما يؤدى الى إرباك سير عمليات التحكيم واللخول في منازعات أخرى حول عزل محكم ما، وهو الأمر الذى يحجم تقديم هذه الطلبات بسوء نية. رابعسا: المـادة (Yr) من نظام التحكيم السعودي تمنح الحق في طلب اتخـاذ إجراءات وقتية أو تحفظية من المحاكم الوطنية قبل انعقاد الهيئة التحكيمية للأطراف، وللهيئة التحكيمية أثناء سير الإجراءات، والأفضل ألا يحصر الحق في طلب إتخاذ هذه

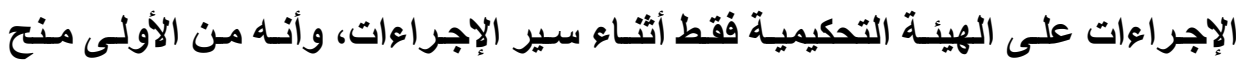
الأطراف أيضاً هذا الحق أثناء سير الإجراءات لمـا يعود بالنفع والتيسير والقدرة على الإسى حماية الحقوق الخاصة بهم، كما لو كان التحكيم يتم خارج المملكة وقد يستغرق إصدار 
الهيئة المعنية بالتدكيم أمر بإجراء وقتي أو تحفظي وقتاً طويلاً، وممـا يدعم هذا القول أنه لا يترتب على اتخاذ هذه الإجراءات توقف سير عملية التحكيم، فلن تستخدم كوسيلة

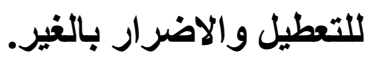
خامساً : أغفل نظام التحكيم السعودي نظام استبدال المحكمين في حالة توقف

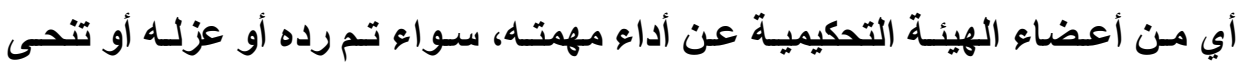

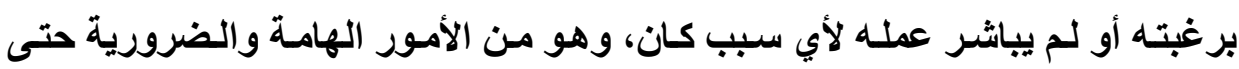
يكون هناك طريقاً يهتدى به في حالة عدم الاتفاق على إجراءات الاستبدال في اتفاق

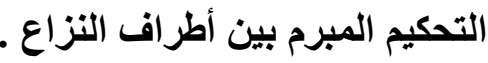




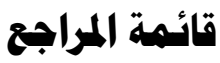

- د. أبو زيــ رضـوان ـ الأسس العامـة في التحكيم التجـاري الدولي ـ دار الفكر

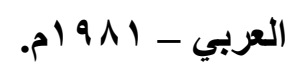

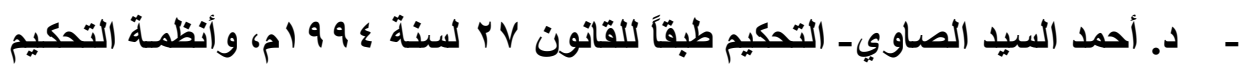

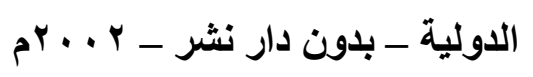

- إجراءات التحكيم طبقاً لقانون التحكيم المصري ووفقاً لأهم قواعد و أنظمة التدكيم

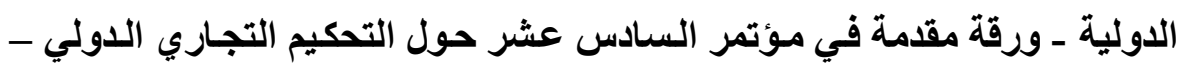

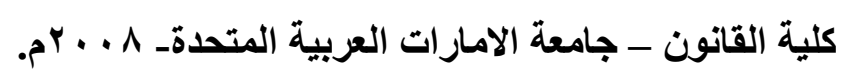

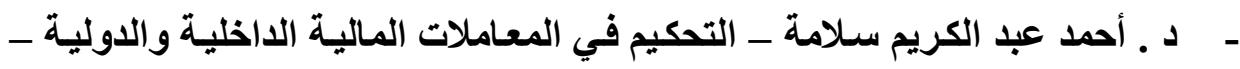

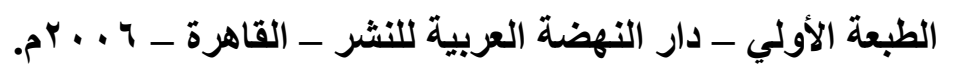

- د. أحمد هندي ـ أصول قانون المرافعات المدنية والتجارية ـ دار الجامعة الجديدة

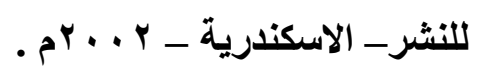

- د. أثرف عبد العليم الرفاعي ـ التحكيم في العلاقات الخاصة الدولية ـ دار الكتب

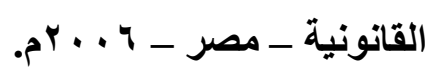

- د. الأنصاري حسن النيداني ـ الأثر النسبي لاتفـق التحكيم ـ دار الجامعة الجديدة

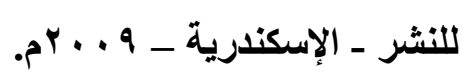

- د.أنور على أحمد الطشي - مبأ الاختصاص بالاختصاص في مجال التحكيم - دار

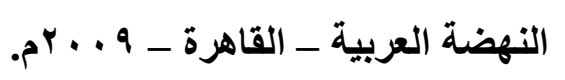

- د. حسني المصري - التحكيم التجـاري الدولي " دراسـة مقارنـة" ـ دار الكتب

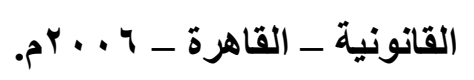


- ـ ـ ـفيظة السيد الحـاد ـ مـدي اختصاص القضاء الـوطني باتخـاذ الإجراءات الوقتية والتحفظية في المنازعات الخاصة الدولية المتفق بشأنها على التحكيم ـ دار

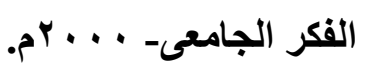

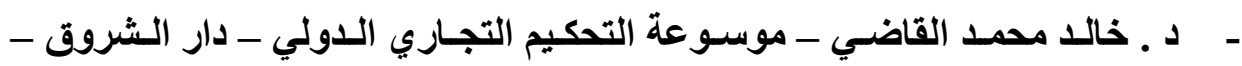

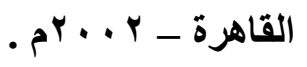

- د. عبد الحميد الأحدب ـ موسوعة التحكيم ـ الكتاب الثاني ـ التحكيم الدولي -

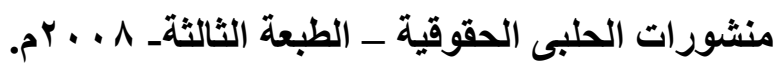

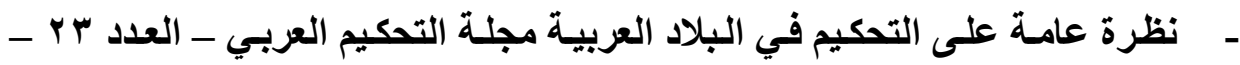

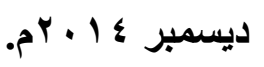

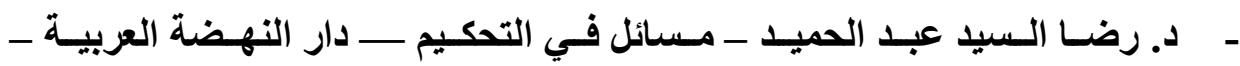

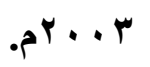

- د. سراج حسين محمد أبو زيد- التحكيم في عقود البترول- رسـالة دكتوراهـ كلية

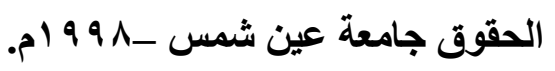

- ـ ـ ـبري أحمد الذيابات - إجراعات التحكيم التجاري الدولي - رسـالة دكتوراه ـ كلية الحقوق جامعة عين شمس - ص ه اب - د. على سـالم إبـراهيم - ولايـة القضاء على التحكيم - رسـالة دكتوراه - كليـة الحقوق - جامعة عين شمس- 999 أم م.

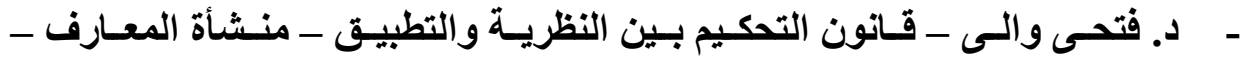

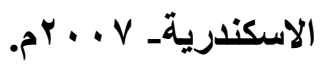


- د. فوزي محمد سامي- التحكيم التجاري الدولي ، دراسة مقارنه في أحكام التحكيم

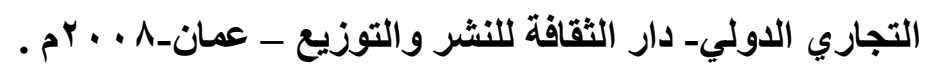

ـ دـ محسن شـفيق ـ التحكيم التجـاري الدولي ــدار النهضة العربيـة ـالقـاهرة ـ

- د.محمد سليم العوا ـ دراسـات في قانون التحكيم المصري والمقارن- بدون دار

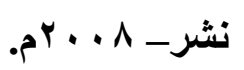

- د محمـود سـمير الشرقاوي ـ الاجـراعات المؤقتـة والتحفظيـة في مجـال التحكيم

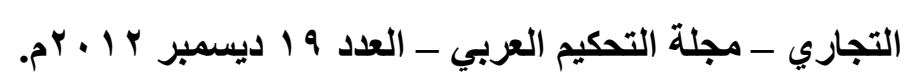

- د. محمود مصطفى يونس - المرجع فى أصول التحكيم - دار النهضة العربيةــ

$$
\text { . } 9
$$

- د. محمد الجمـال، و د. عكاثـة محمد عبد العـال ـ التحكيم في العلاقـات الخاصـة

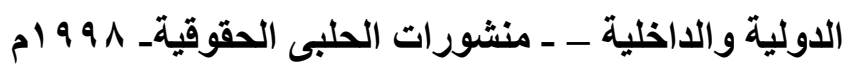

- د. منير عبد المجيد ـ الأسس العامة للتحكيم الدولي والداخلي ـ مصر ـ ه . . ب م . - د. ناصر محمد جمعـان - شـرط التحكيم في العقود التجاريـة "دراسـة مقارنـة"-

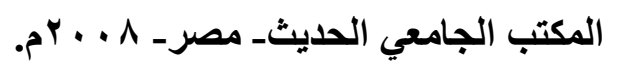

- ـ. ناريمـان عبد القـادر - إتفـاق التحكيم وفقاً لقـانون التحكيم في المـواد المدنيـة

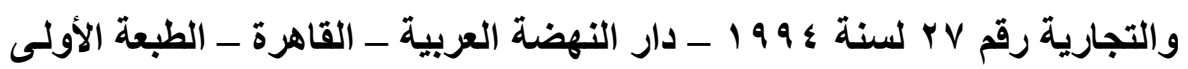

$$
\text { م) } 1999 \text { - }
$$

- د. هدى عبد الرحمن - دور المحكم في خصومة التحكيم وحدود سلطاته ـ دار

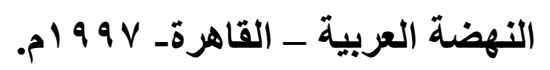


- د. هشام خالد ـ تكوين المحكمة التحكيمية في منازعات التجـارة الدولية ـ المجلد

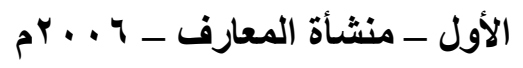

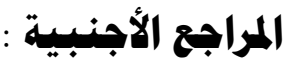

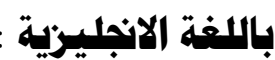

- Anne Bihancov-What is an example of a good dispute resolution clause and why?-Australian Centre for Justice Innovation Civil Justice Research Online- 2014

- Andrew Tweeddale and Keren Tweeddale- Scott v Avery Clauses: O'er Judges' Fingers, Who Straight Dream on FeesSwiss Cottage- 2011.

- Michael H. LeRoy -Misguided Fairness - Regulating Arbitration by Statute: Empirical Evidence of Declining Award Finality- Notre Dame Law Review- Volume 83 | Issue 2- Article 3.

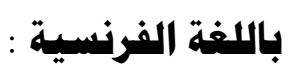

- Jean Robert - L'arbitrage : droit interne et droit international - 6éme- Editions, Dalloz -1993.

- Ph. Fouchard -L'arbitrage et la mondialisation de l'économieMélanges en l'honneur de Gérard Farjat- Paris- 1999. 
-Fouchard, Gaillard et Goldman, Traite de l'arbitrage commercialinternational, ed. Litec- Paris- 1996..

-Voir P. Lalive -Avantages et inconvénients de l'arbitrage ad hoc -Etudesffertes à Pierre Bellet- Paris- 1991.

- J. Robert, L'arbitrage, droit interne et droit international privé, 6e éd-Paris, 1993.

-M. de Boisséson- Le droit français de l'arbitrageinterne et international- 2e éd- Paris- 1990.

\section{الأحكام القضائية : n}

ـ مدونة الأحكام القضائية السعودية الصادرة عن ديوان المظالم .

ـ مجموعة أحكـام محكمة النقض المصرية المنشورة على موقع محكمة الرسـى www. cc.gov. eg

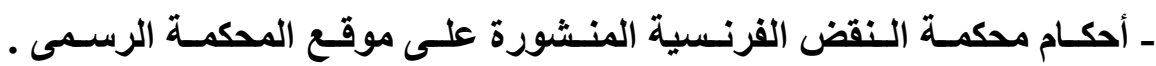
Www.courdecassation.fr

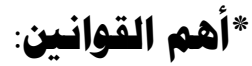

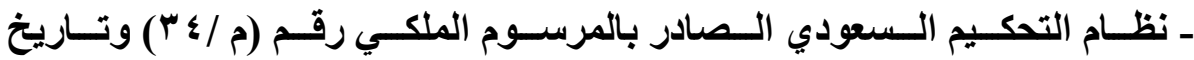
ه $1 \leqslant T / / O / Y \leq$ ـ قانون التحكيم المصري رقم Vr لسنة \& 9 ام ـ ـ قانون التحكيم الانجليزى لسنة ج9 9 ام . 


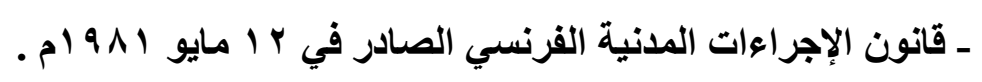
ـ قواعد الأونسيتر ال للتحكيم لسنة ـ 1 ـ بم الصادرة عن لجنة الأمم المتحدة للقانون

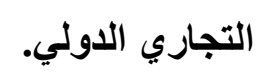

ـ القانون النموذجي للتحكيم التجاري الدولي لسنة هـ9 ام ـ 